\title{
The potential of behavioural change for climate change mitigation: a case study for the European Union
}

\section{Dirk-Jan van de Ven, Mikel González- Eguino \& Iñaki Arto}

Mitigation and Adaptation Strategies for Global Change

An International Journal Devoted to Scientific, Engineering, Socio-Economic and Policy Responses to Environmental Change

ISSN 1381-2386

Mitig Adapt Strateg Glob Change DOI 10.1007/s11027-017-9763-y

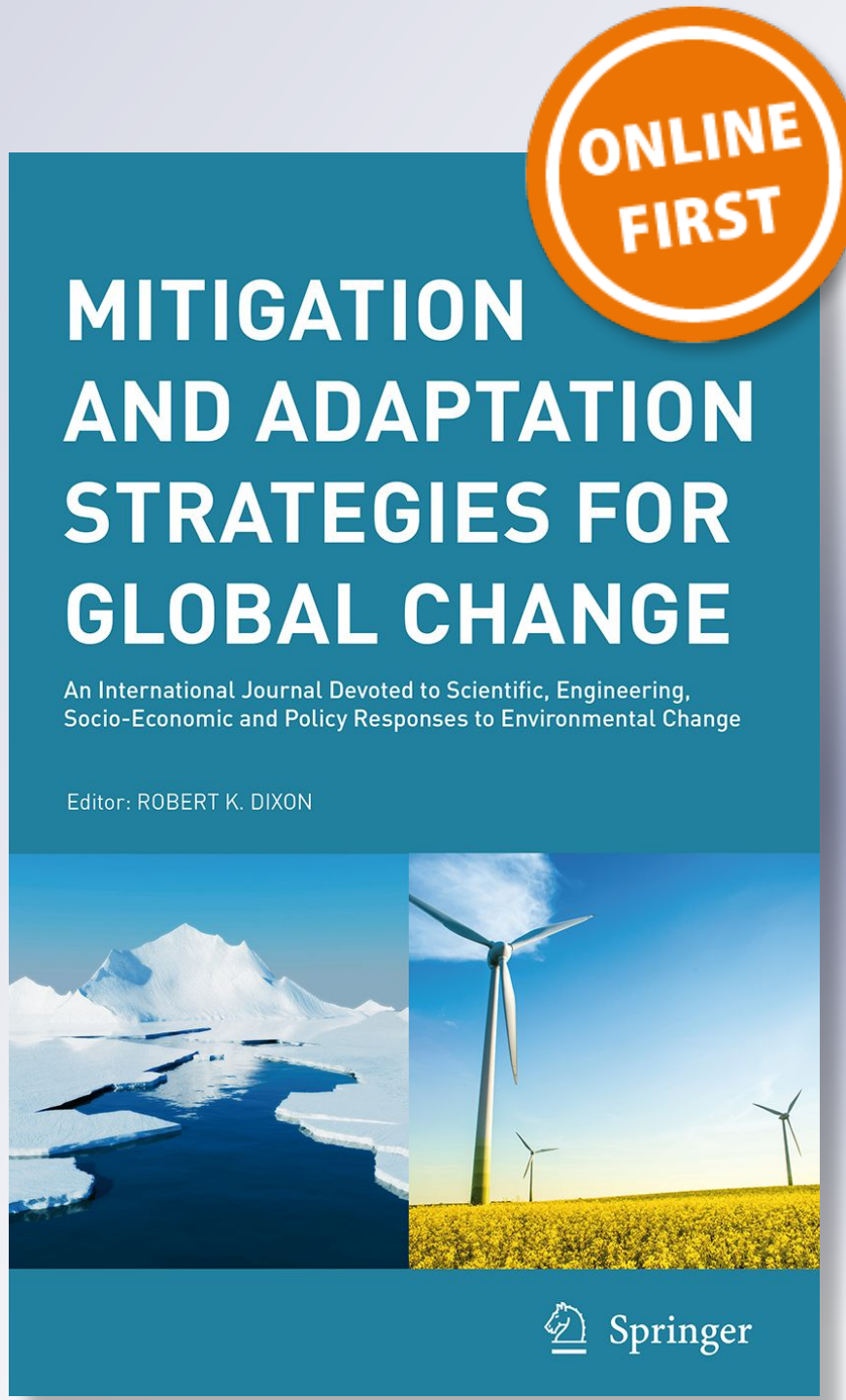

Springer 
Your article is protected by copyright and all rights are held exclusively by Springer Science+Business Media B.V.. This e-offprint is for personal use only and shall not be selfarchived in electronic repositories. If you wish to self-archive your article, please use the accepted manuscript version for posting on your own website. You may further deposit the accepted manuscript version in any repository, provided it is only made publicly available 12 months after official publication or later and provided acknowledgement is given to the original source of publication and a link is inserted to the published article on Springer's website. The link must be accompanied by the following text: "The final publication is available at link.springer.com". 


\title{
The potential of behavioural change for climate change mitigation: a case study for the European Union
}

\author{
Dirk-Jan van de $\operatorname{Ven}^{1}$ (D) Mikel González-Eguino ${ }^{1,2} \cdot$ \\ Iñaki Arto ${ }^{1}$
}

Received: 29 May 2017 / Accepted: 1 September 2017

(C) Springer Science+Business Media B.V. 2017

\begin{abstract}
Mainstream literature on climate change concentrates overwhelmingly on technological solutions for this global long-term problem, while a change towards climate-friendly behaviour could play a role in emission reduction and has received little attention. This paper focuses on the potential climate mitigation by behavioural change in the European Union (EU) covering many behavioural options in food, mobility and housing demand which do not require any personal up-front investment. We use the Global Change Assessment Model (GCAM), capturing both their direct and indirect implications in terms of greenhouse gas emissions. Our results indicate that modest to rigorous behavioural change could reduce per capita footprint emissions by 6 to $16 \%$, out of which one fourth will take place outside the EU, predominantly by reducing land use change. The domestic emission savings would contribute to reduce the costs of achieving the internationally agreed climate goal of the EU by 13.5 to $30 \%$. Moreover, many of these options would also yield co-benefits such as monetary savings, positive health impacts or animal wellbeing. These results imply the need for policymakers to focus on climate education and awareness programs more seriously and strategically, making use of the multiple co-benefits related with adopting pro-environmental behaviour. Apart from that, the relevance of behavioural change in climate change mitigation implies that policyinforming models on climate change should include behavioural change as a complement or partial alternative to technological change.
\end{abstract}

Keywords Climate change $\cdot$ Mitigation $\cdot$ Behavioural change $\cdot$ Diet change $\cdot$ Mobility $\cdot$ Land-use change $\cdot$ Waste recycling $\cdot$ Policy costs $\cdot$ Footprint emissions

Dirk-Jan van de Ven

dj.vandeven@bc3research.org

1 Basque Centre for Climate Change (BC3), Edificio Sede 1-1, Parque Científico de UPV/EHU, Barrio Sarriena s/n, 48940 Leioa, Spain

2 University of the Basque Country (UPV/EHU), Leioa, Spain 


\section{Introduction}

Mainstream literature on climate change concentrates overwhelmingly on technological solutions for this global long-term problem. Research effort has focused primarily on how the portfolio of existing and future technologies can contribute to meet the world's energy demand over the next century and, at the same time, limit greenhouse gas (GHG) emissions so that they are consistent with a stabilisation of temperature increase below $1.5-2{ }^{\circ} \mathrm{C}$ with respect to preindustrial levels. For example, Pacala and Socolow (2004) showed that there is already a portfolio of measures that, if implemented, can deliver a significant reduction of emission during the first half of the century. Fifteen different measures were proposed in that influential paper to reduce GHG emissions (1 Gigatons of carbon (GtC) year ${ }^{-1}$ and option), out of which only one of these measures was a behavioural-based solution: reduce the use of private vehicles by $50 \%$.

The mitigation effort that will be needed is so great that additional changes in human behaviour will be necessary. According to the Intergovernmental Panel on Climate Change (IPCC 2014), 'The existence of limits to adaptation suggests transformational change may be a requirement for sustainable development in a changing climate - that is, not only for adapting to the impacts of climate change, but for altering the systems and structures economic and social relations, and beliefs and behaviours that contribute to climate change and social vulnerability' (technical summary, page 89). Samadi et al. (2017) argue that since behavioural changes towards more sustainable lifestyles have considerable potential to contribute to public policy goals and may even be indispensable for achieving some of these goals, future lifestyle assumptions should be assessed separately from technological assumptions in future energy scenarios.

Apart from a handful of studies focusing on housing and mobility demand (Dietz et al. 2009; Gifford et al. 2011; van Sluisveld et al. 2016), food demand (Bajželj et al. 2014; Hallström et al. 2015; Stehfest et al. 2009) or an overall set of behavioural measures (Faber et al. 2012; Wynes and Nicholas 2017), the total mitigation potential due to behavioural action has received little attention in literature (IPCC 2007; Roy 2012). However, those few studies trying to quantify the impacts of behavioural change show substantive potentials for climate change mitigation. For example, Dietz et al. (2009) examine the achievable near-term reductions by altered adoption and use of available technologies in housing and mobility demand in the United States of America (USA). They found 17 household action types in five behaviourally distinct categories by use of data on the most effective documented interventions that did not involve new regulatory measures. According to this study, the USA could save an estimated 123 million metric tons of carbon per year in 10 years (20\% of total household direct emissions or $7.4 \%$ of US national emissions), with little or no reduction in household well-being. Also for food demand, Bajželj et al. (2014) show a large mitigation potential for behavioural change. Using a global land-system model to estimate the impact of changing food demand on GHG emissions, they show that demand side reductions, such as reducing food waste and adopting a healthy diet, could more than offset the projected increase in GHG emissions from the agricultural sector due to global population growth.

Most of the above-mentioned studies on the potential of behavioural change for climate change mitigation are based on adding up the emission savings of separately calculating behavioural mitigation options (in the case of housing and mobility 
demand) or on sector-specific models (in the case of food demand). Only two studies use a multi-sectoral Integrated Assessment Model (IAM; in both studies using IM$\mathrm{AGE}^{1}$ ) to model the overall impacts of preference changes in housing and mobility demand (van Sluisveld et al. 2016) and food demand (Stehfest et al. 2009). Although IAMs might not be ideal to represent the mitigation impacts of behavioural change due to methodological limitations, the limited representation of lifestyle changes in IAMs and general limitations in integrated assessment (van Sluisveld et al. 2016, pp. 316-317), they are useful to analyse the interaction of behavioural change with other measures, such as technological change or policies.

Since IAMs are commonly used by policymakers to assess different climate scenarios, it is important that the quantitative potential of behavioural changes in these scenarios is highlighted more prominently and independently of technology decisions (Samadi et al. 2017). In recent years, shared socioeconomic pathways (SSPs) have been increasingly used in IAMs to assess socioeconomic uncertainty in future climate scenarios (O'Neill et al. 2017). Each of these SSPs represents a package of background circumstances that greatly influences future scenarios. Future lifestyles form part of these background circumstances, along with many other uncertainties (O’Neill et al. 2014).

This study focuses on the potential climate mitigation by behavioural change in the $\mathrm{EU}^{2}$ that goes beyond the studies by Dietz et al. (2009), van Sluisveld et al. (2016) and Bajželj et al. (2014) as follows: (a) it covers many of the options in food, mobility and housing demand, not only in the energy or food domain and (b) it uses an Integrated Assessment model (Global Change Assessment Model (GCAM) model, see Sect. 2.1) that can capture the direct and indirect implications in terms of emissions. The results will focus on per capita GHG emission savings due to behavioural change - with the recognition that behaviour change is not straightforward and some people will change their behaviour more easily than others. ${ }^{3}$ Finally, this study discusses the co-benefits that are related to many forms of pro-environmental behaviour.

While literature on the potential benefits of pro-environmental behaviour seems scarce, there is extensive literature on the question as of why people behave environmentally friendly and how to boost this kind of behaviour (Poortinga et al. 2004; Ohe and Ikeda 2005; Fujii 2006; Ohtomo and Hirose 2007; Quimby and Angelique 2011; Shwom and Lorenzen 2012; Masud et al. 2015). The primary focus of this study however is the positive question on the extent to which climate-friendly behaviour can contribute to climate mitigation and not on the normative question on how people can adapt their behaviour and what are the appropriate instruments to achieve that. However, since the normative question is obviously related to the positive question, we provide a short summary of the literature on the normative question in Sect. 4.1.

\footnotetext{
${ }^{1}$ Integrated model to assess the global environment, for details: http://themasites.pbl.nl/models/image/index. php/Welcome_to_IMAGE_3.0_Documentation

${ }^{2}$ We focus on the EU-27, so excluding Croatia which joined the EU in mid-2013. The reason behind this is that the GCAM model does not yet include Croatia in the modelled EU-region. Croatia represented about $0.83 \%$ of total population and $0.33 \%$ of total GDP in the European Union in 2015 (source: EuroStat).

${ }^{3}$ Factors like income and household size (Poortinga et al. 2004) and social influences (Staats et al. 2004) are of high importance, among other factors.
} 


\section{Method}

This section is structured as follows. First, we discuss the model in general and the way it has been applied in our study (Sect. 2.1). We then discuss the assumptions made for each modelled behavioural option (Sect. 2.3). Finally, we discuss the baseline and policy scenario that we run on the background of these options (Sect. 2.4).

\subsection{The GCAM model}

This study applies the GCAM, an integrated assessment model that links the world's energy, agriculture and land use systems with a climate model. GCAM traces its origin to a model developed by Edmonds and Reilly (1985) and was previously known as MiniCAM (see Edmonds et al. 1997). It is a community model developed and run at the Joint Global Change Research Institute, University of Maryland. GCAM was one of the four models chosen by the IPCC to create the Representative Concentration Pathways (RCPs) for the IPCC's Fifth Assessment Report (see Thomson et al. 2011).

GCAM is a dynamic recursive economic partial equilibrium model. It is driven by assumptions about population size and labour productivity that determine gross domestic production (GDP) in 32 geopolitical regions, operating on 5-year time steps from 1990 to 2100. The model connects emissions and atmospheric concentrations of GHGs, carbonaceous aerosols, sulphur dioxide and reactive gases to socioeconomic activities and provides estimates of the associated climate impacts. An important feature of the GCAM architecture is the terrestrial carbon cycle model embedded within the agriculture-land-use system model. Thus, all land uses and land covers, including the non-commercial lands, are fully integrated into the economic modelling in GCAM. This coverage gives GCAM the capability to model socioeconomic preferences and policies that jointly cover emissions in all activities in the energy, agricultural and forestry sectors. These properties make the model suitable for comparing the potential savings of all greenhouse gases from a wide range of behavioural trends in the food, mobility and housing sectors. For more details on the GCAM model, see Calvin et al. (2011).

\subsection{Behavioural change modelling in GCAM}

We have used $\mathrm{GCAM}^{4}$ in a way that differs significantly from previous studies. The model is usually used to test the impact of mitigation polices. Since climate policies, energy policies and land policies usually focus on either the price or the production of certain goods, services or gases, demand is indirectly impacted due to a change in prices. In contrast, and following van Sluisveld et al. (2016) using another IAM model, we use GCAM to model preference changes by consumers in two GCAM regions, EU-15 and EU-12. ${ }^{5}$ Indirectly, these preference changes will have an impact on prices and production of goods and services, which will have an impact on GHG emissions. Although we limit the modelling to EU-15 and EU-12, the impacts of the modelled preference changes will be analysed on a global level (see Appendix 2). For these two regions, we have also developed an independent and interconnected household waste

\footnotetext{
${ }^{4}$ We used GCAM version 4.2. See http://jgcri.github.io/gcam-doc/v4.2/overview.html for a detailed description.

${ }^{5}$ EU-15: Germany, UK, France, Italy, Spain, Austria, Netherlands, Belgium, Portugal, Sweden, Denmark, Finland, Greece, Ireland and Luxembourg. EU-12: Czech Republic, Estonia, Cyprus, Latvia, Lithuania, Hungary, Malta, Poland, Slovakia, Slovenia, Bulgaria and Romania.
} 
module in order to estimate the impacts of waste recycling by consumers (see the Appendix 2 for more details on this module).

\subsection{Options for behavioural change}

In 2008, the total GHG footprint of the average EU-27 consumer equalled 9.73 tons of $\mathrm{CO}_{2}$ equivalent. Food demand contributed to $17 \%$ of this footprint, whereas mobility and housing demand contributed respectively to 23 and $29 \%$ of per capita footprint emissions (Arto et al. 2012). This study focuses on the behavioural options within these three consumption categories: food, mobility and housing. See Table 1 for the specific options within each category. These options are chosen for their behavioural aspects. The idea behind the selection of these options is that they are free of charge, can be adopted from 1 day to another without the need of personal monetary investments ${ }^{6}$ and do not significantly impact the quantity of personal needs in terms of food, mobility and housing. ${ }^{7}$ Whereas some options are mutually exclusive, others might limit the effectiveness of other options. Finally, we will also focus on a combination of options to see the total mitigation potential. To clarify what every option includes, and how it is modelled, we will explain each of the options in detail in the rest of this section.

Although we calculate the potential mitigation of all the listed options in absolute terms, we present them on a per capita level. The reasoning behind this is as follows: while it is implausible that all EU-27 residents take up a specific behavioural mitigation method from today or tomorrow onwards, for every specific individual, it is not at all implausible to change his/her behaviour from 1 day to the next. Also, while some individuals are convinced about reducing their food waste and joining a car sharing programme, others might prefer to follow a healthy diet and recycle their waste. Since preferences differ between individuals, we chose to show the mitigation potential and co-benefits on a per capita level.

Some of these behavioural options would imply monetary savings for the consumer (see also Sect. 3.6 on co-benefits). Literature suggests that these monetary savings will yield rebound effects, decreasing its effectiveness on total emission savings (Druckman et al. 2011; Grabs 2015). The final rebound effect depends on where the monetary savings are spent on. The lower the GHG intensity of the re-spending of savings, the lower is the rebound effect of behavioural change. In some cases, re-spending could even save more emissions, if they are invested in, for example, rooftop solar installations or electric vehicles to replace their previous vehicle. Since we did not model any rebound effects, we implicitly assume that the re-spending of eventual savings have a negligible GHG intensity on average. Given the intrinsic motivation that is necessary to adopt green behaviour, the assumption that this intrinsic motivation will extend to eventual re-spending of savings seems reasonable.

\subsubsection{Food demand}

This section explains how behavioural options regarding food consumption are modelled. See Kyle et al. (2011) for the methods and data sources used to model the agricultural and land-use system into GCAM.

\footnotetext{
${ }^{6}$ Some behavioural options, such as public transport commuting, joining a car-sharing programme and waste recycling might require investment from public or private entities to meet the consumer's demand.

${ }^{7}$ In contrast with Wynes and Nicholas (2017), who estimate the impact of more rigorous behavioural changes such as having one fewer child or living completely car free.
} 
Table 1 List of behavioural options

\begin{tabular}{lcc}
\hline Food demand & Mobility demand & Housing demand \\
\hline $\begin{array}{c}\text { Healthy diet, vegetarian } \\
\text { diet, vegan diet and } \\
\text { food waste reduction }\end{array}$ & $\begin{array}{c}\text { Public transport commuting, carpool } \\
\text { commuting, teleworking, urban } \\
\text { cycling, car sharing/car club, avoid } \\
\text { short flights, closer holidays and eco-- } \\
\text { driving }\end{array}$ & $\begin{array}{c}\text { Reduce heating/cooling, organic waste } \\
\text { recycling/composting, paper waste } \\
\text { recycling and plastic/metal/glass waste } \\
\text { recycling }\end{array}$ \\
\hline
\end{tabular}

Healthy diet The assumed average healthy diet is considered to be 'healthy' on the basis of nutritional evidence (Willett 2011; WHO 2003; American Heart Association 2014). Following Bajželj et al. (2014), we respect the dietary preferences in the EU-27, but with some foods that are deemed unhealthy above or below certain levels capped. See Table 2 for the precise current and assumed healthy diet for both EU-15 and EU-12 $2^{89}$

Vegetarian diet A vegetarian diet does not include any meat but does include dairy products and potentially fish products. We modelled this option by setting all the consumption of cow meat, calve meat, pigmeat, poultry meat, mutton and goat meat to zero. The reduction of calories will be replaced with the GCAM category MiscCrop ${ }^{10}$ (including, between others, all kind of legumes, vegetables, fruits and nuts) until the daily net amount ${ }^{11}$ of 2500 cal person $^{-1}$ day $^{-1}$ is reached.

Vegan diet Different than the vegetarian diet, the vegan diet does also not include milk and fish products. The modelling method is exactly the same, replacing these products with MiscCrop products until the daily net amount ${ }^{12}$ of 2500 cal person $^{-1}$ day $^{-1}$ is reached.

Food waste reduction Since waste is a rather subjective term, there are several approaches to account for food losses. Technically, we could consider food used as feed for animals as food waste, as it involves a loss in final calories for human purposes. Furthermore, we can distinguish waste at the agricultural, postharvest, processing, distribution and consumption levels (Kummu et al. 2012; Bajželj et al. 2014) and we can further distinguish consumption waste between avoidable, possibly avoidable (that some people eat and some people do not, like bread crusts or potato skins) and unavoidable food waste like vegetable peelings and meat carcasses (Ventour 2008). Since we are focusing on behavioural mitigation, we will focus solely on avoidable (including $50 \%$ of possibly avoidable) food waste on the consumer level.

Estimates from the Food and Agriculture Organisation of the United Nations (FAO 2011) are used to separate out the percentage of consumption waste from final food demand. Since the food demand estimations in GCAM are also based on FAO data, this seems the most

\footnotetext{
${ }^{8}$ We separate the diet in EU-15 and EU-12 due to their relevant dietary preferences. We use the estimations of Bajželj et al. (2014) for West-Europe as a proxy for EU-15 and the estimations for East-Europe as a proxy for EU-12.

${ }^{9}$ Since the food categories in GCAM do not exactly match with the categories in Table 2, we made sure that we applied the absolute changes in $\mathrm{kcal} /$ person/day of the GCAM food category containing the relevant category of Table 2.

${ }^{10}$ See Table A2 in Appendix A in Kyle et al. (2011) for the total list of products that are included in MiscCrop.

${ }^{11}$ Net amount of calories after the subtraction of all producer and consumer food waste

12 See footnote 5
} 
Table 2 Healthy diet assumptions

\begin{tabular}{|c|c|c|c|c|c|}
\hline \multirow[t]{2}{*}{ Food } & \multicolumn{2}{|l|}{ Current $\operatorname{diet}^{\mathrm{a}}$} & \multirow{2}{*}{$\begin{array}{l}\text { Healthy diet }^{\mathrm{b}} \\
\text { EU-27 } \\
(\text { kcal person }\end{array}$} & \multicolumn{2}{|c|}{ Diet change } \\
\hline & $\begin{array}{l}\text { EU-15 } \\
\left(\text { kcal person }^{-1} \text { day }^{-1}\right)\end{array}$ & $\begin{array}{l}\text { EU-12 } \\
\left(\text { kcal person }^{-1} \text { day }^{-1}\right)\end{array}$ & & $\begin{array}{l}\text { EU-15 (\% } \\
\text { change) }\end{array}$ & $\begin{array}{l}\text { EU-12 (\% } \\
\text { change) }\end{array}$ \\
\hline Vegetables & 58 & 64 & 136 & 134 & 113 \\
\hline Fruits & 91 & 53 & 119 & 30.8 & 125 \\
\hline Sugar/sweeteners & 318 & 308 & 150 & -53 & -51 \\
\hline Vegetable oils & 514 & 326 & 360 & -30 & 10.4 \\
\hline Red meat ${ }^{\mathrm{c}}$ & 260 & 180 & 57 & -78 & -68 \\
\hline Poultry meat $^{\mathrm{d}}$ & 67 & 70 & 70 & 4.5 & 0 \\
\hline Eggs & 39 & 48 & 40 & 2.6 & -17 \\
\hline Milk products & 391 & 313 & 300 & -23 & -4.2 \\
\hline Fish products ${ }^{\mathrm{e}}$ & 56 & 40 & 50 & -11 & 25 \\
\hline All other food ${ }^{f}$ & 933 & 1209 & 1218 & 30.5 & 0.7 \\
\hline Total & 2727 & 2611 & 2500 & -8.3 & -4.3 \\
\hline
\end{tabular}

${ }^{\text {a }}$ FAO (2010)

${ }^{\mathrm{b}}$ Applying caps as interpreted by Bajželj et al. (2014)

${ }^{\mathrm{c}}$ Red meat category consists of bovine meat, pigmeat, mutton (Ovis aries) and goat meat (Capra aegagrus). Cultural preferences between EU-15 and EU-12 are respected

${ }^{\mathrm{d}}$ Gallus gallus

${ }^{\mathrm{e}}$ Due to limitations in global fisheries, these are kept constant at an EU-27 average

${ }^{\mathrm{f}}$ Respecting the cultural food preferences between EU-15 and EU-12

sensible source for making assumptions on food waste. See Table 3 for the assumed food waste in EU-27 for different types of food.

A food waste reduction potentially reduces GHG emissions in two ways: less final food demand leads to less agricultural emissions and less food waste leads to less waste emissions. The latter, however, depends on what happens with the food waste: emission savings from food waste reduction will be greater if this food waste would otherwise get landfilled, but the net effect would be smaller if the food will otherwise be composted and used as a fertiliser, replacing mineral fertilisers (Bogner et al. 2007). The current EU-27 recycling rate will be assumed for this behavioural option, unless we estimate the combined effect of Food Waste

Table 3 Food consumption and waste in EU-27, 2010

\begin{tabular}{llll}
\hline Food & $\begin{array}{l}\text { Total EU-27 consumption } \\
\left(\text { kcal person }^{-1} \text { day }^{-1}\right)\end{array}$ & $\begin{array}{l}\text { Total waste } \\
(\% \text { of total consumption })\end{array}$ & Consumer waste $^{\mathrm{b}}$ \\
\hline Cereals & 1177 & 34 & 22 \\
Roots and tubers & 136 & 52 & 10 \\
Oilseeds and pulses & 863 & 19.5 & 3 \\
Fruits and vegetables & 288 & 46 & 13.5 \\
Meat & 570 & 22 & 10 \\
Fish and seafood products & 180 & 31 & 8 \\
Milk and milk products & 315 & 12.5 & 7 \\
Total & 3529.9 & 28.1 & 12.2 \\
\hline
\end{tabular}

${ }^{a}$ Includes all related industry and consumer wastes (FAOSTAT)

${ }^{\mathrm{b}}$ FAO (2011), Global food losses and food waste - extend, causes, and prevention 
Reduction and Organic Waste Recycling/composting. ${ }^{13}$ For more details on the assumptions in the waste module, see Appendix 2.

\subsubsection{Mobility demand}

This section explains how behavioural options regarding to transport use are modelled. For a detailed documentation on how the transport system is modelled in GCAM, see Mishra et al. (2013). The GCAM model uses estimates from the TREMOVE model (EC 2010a) for the base-year calibration values in EU-15 and EU-12. Although the data from the TREMOVE model is based on modelled estimates rather than real observations, for reasons of consistency we extract data on more detailed variables (such as the share of urban transport or commuting transport in total transport demand) from the same model. See Appendix 1 for more background details on these options, if applicable.

Public transport commuting For this behavioural option, we assumed that all mobility demand in EU-27 related to commuting (i.e. going from home to work and back) will be met by public transport services (i.e. bus and rail transport). We extrapolate the current regional public transport mix (i.e. the share of bus and rail transport) to meet all mobility demand for commuting from 2015 onwards.

Carpool commuting Similar to the previous option, we focus again on the current share of commuting in EU-15 and EU-12 mobility demand. Similar to Dietz et al. (2009), this behavioural option is translated into numbers by stating a load factor of 2 for every commute car trip, which is a minimal definition of car pooling. Current mobility demand for commuting that is met by public transport and bike/motorbike use is left untouched.

Teleworking In order to model the effects of working 1 day week ${ }^{-1}$ from home, we have simply deducted the demand for passenger commuting by one fifth. ${ }^{14}$ This method implicitly assumes that EU-27 citizens would normally work 5 days week $^{-1}$ away from home.

Urban cycling There are no easy and straightforward assumptions to make on the potential share for bicycles in total passenger transport. Variable factors like the trip distance and street steepness limit the realistic potential of cycling as an alternative transport mode. According to the Central Bureau for Statistics (2016), the average trip distance for bicycle trips in the Netherlands between 2010 and 2014 was around $3.5 \mathrm{~km}$. Moreover, while the bicycle was the main transport mode for trips up to $5 \mathrm{~km}$, its share was very marginal for trips longer than $5 \mathrm{~km}$. Apart from business trips and emergency services, bicycle use is proportionally distributed between a wide range of travel purposes in the Netherlands. Naturally, street steepness is an important factor for the cycling potential, explaining (among other reasons) why cycling is relatively popular in most cities in the Netherlands, Northern Belgium, Northern Germany and Denmark.

\footnotetext{
${ }^{13}$ The combined effect of food waste reduction and organic waste recycling applies to two out of three behavioural profiles in Sect. 3.3.

${ }^{14}$ Note that we did not model any changes in heating or cooling demand, assuming that the individual's heating/ cooling demand at home and at work will be equal.
} 
Because of these facts, we aim to quantify the potential of bicycle usage for any purpose in urban areas only: trips within urban areas are on average quite short and streets within cities are generally flatter than streets outside cities. For non-urban passenger trips, it would be too difficult to generalise the potential for all EU-27 member states. As a benchmark for the urban cycling potential, we therefore expand the urban cycling rate in the Netherlands to the whole EU-27.

Car sharing/car clubs Over the last decade, car-sharing programs have been increasing significantly in popularity in the USA and Europe. Car sharing is an innovative mobility option that allows individuals to pay for and use automobiles - on an as-needed basisthrough membership programs (Transportation Research Board 2005). Although users of car-sharing programs generally tend to drive less on average compared with car owners, due to the constant (rather than decreasing) marginal costs of driving that are faced in a car-sharing programme (Chen and Kockelman 2015), we are assuming an equal amount of passenger kilometres driven by cars in this behavioural option. This enables us to solely focus on the environmental benefits from car sharing, without assuming any impact on the total amount of driven kilometres.

There are two main channels through which car sharing would decrease emissions per passenger-kilometre: lower industrial emissions related with car production and a higher average fuel efficiency due to a faster replacement rate of car-club vehicles compared with privately owned vehicles (Chen and Kockelman 2015). Although the faster replacement rate due to higher utilisation rates of car-club vehicles do limit the savings in industrial emissions, the latter does not seem to be cancelled out completely. In other words, intensively used carclub vehicles seem to drive a higher amount of total kilometres during their significantly shorter lifetimes. ${ }^{15}$ See Appendix 1 for a detailed overview on the assumptions made in order to model this behavioural option.

Avoid short flights The idea behind this behavioural option is to avoid flying whenever there is a 'realistic' travel alternative. With a realistic alternative, we mean another way to get to the desired destination using a different transport mode and that does not take more than $10 \mathrm{~h}$ of travelling. We found that about $25 \%$ of all passenger kilometres on intra-EU flights are avoidable by these standards and implicitly assume that it remains $25 \%$ until 2050 (see Appendix 1 for details).

This behavioural option assumes that these $25 \%$ of passenger kilometres will instead be travelled by a mix of coach, train, high-speed-rail and carpool transport.

Closer holidays This behavioural option focuses on intercontinental leisure flights. We assume here that $50 \%$ of all intercontinental leisure trips (with an average distance of about $5000 \mathrm{~km}$ per trip) are replaced by intra-EU trips with an average trip distance of $1000 \mathrm{~km}$. Intra-EU air transportation will be assumed to serve all these replacing intra-EU trips, unless this behavioural option is combined with the previous one ('avoid short flights').

\footnotetext{
${ }^{15}$ This could be supported by the argument that due to their intensive usage, car-sharing vehicles need significantly more maintenance over its lifetime. GHG emissions related to maintenance are a lot lower than those related to production of vehicles (own elaboration based on the World Input-Output Database (WIOD)).
} 
Eco-driving Here we focus on the application of 'eco-driving' by car drivers. Eco-driving is a term used to describe energy efficient use of vehicles. It is a relatively easy way to reduce fuel consumption from road transport so that less fuel is used to travel the same distance. ${ }^{16}$ Although training might be necessary, every driver can choose to adapt this driving style, making it purely behavioural. Apart from fuel savings, eco-driving also avoids aggressive driving behaviour and is expected to increase road safety in general. ${ }^{17}$ Eco-driving techniques will be applied to all car-driven kilometres in this behavioural option.

\subsubsection{Housing demand}

For housing demand, we build partly on the building sector structure in GCAM (Kyle et al. 2010) and for another part on an innovation to the GCAM model zooming in on the municipal waste sector.

Reduce heating and cooling For the effects of a voluntary reduction in heating consumption in the winter season, we assumed a thermostat set-back from the average 21 to $20{ }^{\circ} \mathrm{C}$. Such an indoor temperature change can be easily compensated by wearing extra clothing. Additionally, we assume a reduced use of air conditioning in summer by increasing the target temperature from 25.5 to $26.5{ }^{\circ} \mathrm{C}$.

Waste recycling We all produce waste: on average, each of the 500 million people living in the EU throws away around half a tonne of household rubbish every year (EC 2010b). The environmental impact of this waste greatly varies with how it is treated: while landfilling of waste leads to significant GHG emissions, recycling of waste into new products actually reduces emissions. The treatment of waste greatly depends on whether different types of waste are properly separated by the consumer or whether it is mixed altogether: $92 \%$ of all separated waste in EU-27 was recycled in 2010, while only $8 \%$ of all mixed waste was recycled in the same year. ${ }^{18}$ The other $92 \%$ of mixed waste ended up in either landfills, open burning sites or was incinerated with energy recovery, all with GHG emissions as a result. In total, $43.6 \%$ of all treated waste in the EU consisted of mixed waste of which more than half was generated by households (Eurostat 2016). We modelled a waste module into GCAM in order to measure the impacts of waste recycling by citizens. See the Appendix 2 for a detailed explanation on the assumptions made for this module.

Organic waste This behavioural option assumes that all organic waste from households will be separated by the consumer, and therefore composted rather than landfilled or incinerated, or directly composted at home by the consumer. The produced compost will be used to replace mineral fertilisers and sequester some of the carbon to the soil.

Paper/carton waste This behavioural option assumes that all consumer paper waste will be recycled and used for producing new paper. Note that in 2010, the EU was the region with the

\footnotetext{
$\overline{16} \mathrm{http} / /$ www.ecodriver-project.eu/

${ }^{17}$ See footnote 16 .

${ }^{18}$ Here, we are ignoring wooden pellets, which is a significant separated waste stream that usually ends up in waste incinerators for practical reasons.
} 
highest amount of paper waste recycling globally (68\%; European Declaration on Paper Recycling (EDPR) 2015), so extra gains from recycling will be limited compared with other regions.

Plastic/metal/glass waste This behavioural option assumes the recycling of all plastic, metal and glass waste by consumers. We assume the composition of this category (i.e. the relative amount of plastics, metal and glass) will stay the same over time.

\subsection{Baseline emissions and comparison}

All behavioural options are modelled upon the baseline scenario with no climate policy. As a baseline, we use the 'middle of the road' shared socioeconomic pathway (SSP2) as defined by O'Neill et al. (2017) in order to avoid strong assumptions on lifestyle changes in the baseline scenario. This pathway has been modelled within GCAM (version 4.2 - see also, CapellánPérez et al. 2014), including a new waste module (explained in Appendix 2) to capture the impact of waste reduction and recycling by consumers.

To measure the impact of behavioural change on climate policy costs (see Sect. 3.4), we assumed a climate policy based on the Nationally Determined Contribution (NDC) adopted by the EU according to the Paris Agreement, promising GHG emission reductions up to $80 \%$ by 2050 compared with 1990 emission levels. ${ }^{19}$ Figure 1 shows the modelled GHG emissions for the baseline scenario with and without climate policy.

Apart from the GHG emissions in EU itself, from a consumption-based approach European citizens would also be responsible for a significant amount of GHG emissions in other parts of the world through consumption of imported goods (Arto et al. 2016). Similarly, consumers in other regions are responsible for GHG emissions inside the EU. Some of the behavioural mitigation options have a significant impact on GHG emissions in other parts of the world, and so reduce the total carbon footprint without contributing to the EU emission targets, as these are not assigned as EU emission savings according to the Paris Agreement. However, since this study focuses on the per capita emission savings due to behavioural change, it should not matter whether these savings take place in his/her house, in a neighbouring country or on the other side of the world. Therefore, we count the total per capita emission savings (regional and global) for every behavioural option and, to have some kind of reference point, compare those with the domestic EU-27 emissions per capita.

\section{Results}

\subsection{Overview}

This section shows the results of this study and put these in perspective. Table 4 shows an overview of the total per capita GHG emission savings relative to the accumulated baseline emissions for the period 2011-2050, assuming that these behavioural options would be adopted immediately. Apart from these savings, it shows the share of fossil fuel and industry

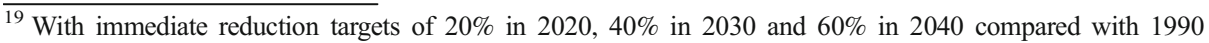
emission levels. http://www4.unfccc.int/submissions/indc/Submission\%20Pages/submissions.aspx
} 


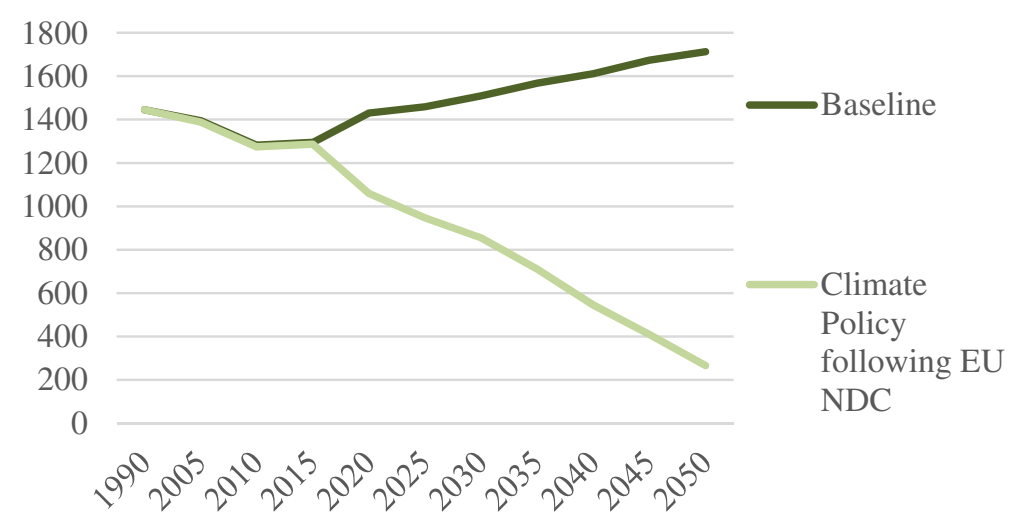

Fig. 1 Carbon emissions in EU-27 region until 2050 in two scenarios (million tons of carbon-eq)

(FFI) $\mathrm{CO}_{2}{ }^{20}$ emission savings within the total GHG emission savings. Finally, the table also shows the share of emissions that are saved domestically within the EU-27 region. All other emission savings have been realised in other regions in the world.

\subsection{Discussion of individual results}

\subsubsection{Food demand}

As Table 4 shows, behavioural change in the demand for food leads to very significant GHG emission savings. For example, adopting a healthy diet would reduce accumulated per capita GHG emissions between 2011 and 2050 by 5.3\%, only 4.6\% of these GHG emission savings are fossil fuel-related $\mathrm{CO}_{2}$ emissions and $58.9 \%$ of these emission savings will occur within the EU. Fossil fuel-related $\mathrm{CO}_{2}$ emissions only account for a very marginal share of all foodrelated emission savings. Instead, methane emission savings from the livestock industry, abated nitrogen oxides from soil utilisation and negative land use change emissions due to decreasing land pressure from the agricultural system add up to the gross of the GHG savings due to behavioural change in the food sector. The majority of emission savings for each of the options is due to land use change (i.e. avoiding deforestation), mainly outside of the EU.

It is important to keep in mind that a combination of food waste reduction with either of the diet changes strongly diminishes the impact of a food waste reduction. This is due to the fact that the majority of emissions in the food sector comes from meat consumption, and if less meat is consumed, less is wasted as well.

\subsubsection{Mobility demand}

In comparison with food demand, behavioural change in mobility demand leads to predominantly domestic $\mathrm{CO}_{2}$ savings. Generally, every option yields $\mathrm{CO}_{2}$ savings due to either a reduction of car or air travel. The fact that not all emissions savings are domestic $\mathrm{CO}_{2}$ emissions has to do with the emissions related to energy products in other regions, predominantly those from unconventional oil. The only exception regarding the source of emission savings in the transport sector is the behavioural option of car sharing/car clubs. This option

${ }^{20}$ FFI $\mathrm{CO}_{2}$ includes all $\mathrm{CO}_{2}$ emissions related to fossil fuel use but no $\mathrm{CO}_{2}$ emissions from land use change 
Table 4 Overview of GHG emission savings per behavioural option relative to the accumulated GHG emissions from 2011 to 2050 in the baseline scenario (see Sect. 2.4)

\begin{tabular}{llll}
\hline Behavioural option & \multicolumn{2}{l}{ Avoided GHG emissions } & \\
\cline { 2 - 4 } & Total 2011-2050 & \% CO $_{2}(\mathrm{FFI})^{\mathrm{a}}$ & \% domestic $^{\mathrm{b}}$ \\
\hline Food demand & & & \\
$\quad$ Vegan diet & $-8.2 \%$ & 3.6 & 66.1 \\
Vegetarian diet & $-7.0 \%$ & 4.7 & 51.0 \\
Healthy diet & $-5.3 \%$ & 4.6 & 58.9 \\
Food waste reduction & $-2.4 \%$ & 3.1 & 49.5 \\
Mobility demand & $-0.7 \%$ & & 86.2 \\
Public transport commuting & $-1.2 \%$ & 93.1 & 89.3 \\
Carpool commuting & $-0.3 \%$ & 92.3 & 89.1 \\
Teleworking & $-0.6 \%$ & 92.3 & 89.3 \\
Urban cycling & $-1.1 \%$ & 92.8 & 89.6 \\
Car sharing/car club & $-0.5 \%$ & 87.3 & 88.1 \\
Avoid short flights & $-0.5 \%$ & 93.2 & 89.4 \\
Closer holidays & $-0.6 \%$ & 93.4 & 89.0 \\
Eco-driving & & 92.3 & 93.6 \\
Housing demand & $-0.6 \%$ & 88.7 & $125.9^{\mathrm{c}}$ \\
Reduce heating/cooling & $-1.1 \%$ & 8.1 & 92.9 \\
Organic waste recycling/composting & $-0.6 \%$ & 86.2 & \\
Paper waste recycling & $-1.7 \%$ & 93.9 & \\
Plastic/metal/glass waste recycling & & & \\
\hline
\end{tabular}

${ }^{\text {a }}$ Fossil fuel and industry: includes all $\mathrm{CO}_{2}$ emissions related to fossil fuel use but no $\mathrm{CO}_{2}$ emissions from land use change

${ }^{\mathrm{b}}$ Share of emission reductions within EU-27 region

${ }^{c}$ Since this option reduces $\mathrm{CO}_{2}$ sequestration from foresting, i.e., increases GHG emissions in other regions (by reducing demand for forest products), more than $100 \%$ of emission reductions occur in the within EU-27 region

implicitly suggests that fewer cars are produced, and therefore mainly leads to savings in industrial emissions. However, about $37 \%$ of the car-sharing emission savings are due to an increasing average fuel efficiency of the vehicle stock due to a higher replacement rate of heavily used shared cars.

One rather surprising result is that commuting by carpooling is more beneficial than commuting by public transport. It is important to keep in mind that we implicitly assumed that the supply of public transport facilities will proportionally increase with higher utilisation of public transport. This means that the load factor of every bus and train does not change as a result of higher utilisation, whereas the load factor of cars does change as a result of carpooling. We are aware that this assumption might be subject to debate and that we might expect a higher load factor for trains and buses if more people decide to use them due to economics of density (Caves and Christensen 1988). However, since the spatial dimension is missing in GCAM, it is hard to provide consistent estimates on the extent to which load factors should increase due to higher use of public transport systems.

\subsubsection{Housing demand}

Emissions in housing demand are mainly related to waste recycling. Table 4 shows that reducing heating in winter and cooling in summer has only a marginal effect on total emission savings. The recycling/composting of organic waste leads to mainly methane emission savings 
due to reduced landfill emissions - the emission savings due to replacement of mineral fertilisers by compost and carbon sequestration by the use of compost does only marginally weigh up against the increased composting emissions. By contrast, recycling of paper, plastic, metal and glass waste predominantly impact the demand for industrial energy, since it costs significantly more energy to make these materials from raw materials than from recycled materials.

As explained in Sect. 2.3.3 and Appendix 2, we assume that separated waste will always be recycled, whereas mixed waste will always be landfilled or burned. However, there exist technologies that can filter out certain types of waste from initially mixed household waste in order to recycle it. Some of these technologies are already in use, for example for separating metal waste. The impact of plastic/metal/glass recycling might therefore be overestimated, as some of these products might anyway be recycled in the future, with or without the contribution of the consumer.

\subsection{Behavioural profiles}

In order to provide an estimate of the total potential emission reduction we cannot simply add up the savings in all categories. Some options are mutually exclusive (such as the diet choices), and other options limit the impact of each other (for example, diet change and food waste reduction or carpooling, eco-driving and teleworking). Therefore, we have described three different profiles for the adoption of green behaviour, each with a different mix of behavioural options that are adopted. Following Autio et al. (2009), each profile is intended to represent a realistic behavioural style that people can identify themselves with, ranging from a very active to a more passive form of behavioural change. Unlike Autio et al. (2009), however, the mitigation effectiveness of each of our behavioural profiles is explicitly modelled. See Table 5 for the behavioural options included for each profile.

Enthusiastic profile The enthusiastic adapter is the typical person that does anything in his/her means to limit the personal footprint. He or she does not eat any meat or other animal products, does not unnecessarily waste any food, does not have a car, uses a bicycle whenever possible or public transport otherwise, applies eco-driving techniques using rental cars when travelling to places impossible to reach without a car, tries to avoid flying by taking alternative transport and by avoiding far destinations, prefers to put some extra clothes in winter or less clothes in summer instead of putting the thermostat or $\mathrm{A} / \mathrm{C}$ higher and separates all types of household waste.

Table 5 List of behavioural options adopted for each profile

\begin{tabular}{lcc}
\hline 'Enthusiastic profile' & 'Conscious profile' & 'Convenient profile' \\
\hline $\begin{array}{l}\text { Food } \\
\text { Vegan diet and food waste reduction }\end{array}$ & Healthy diet and food waste reduction & Food waste reduction \\
$\begin{array}{l}\text { Mobility } \\
\begin{array}{l}\text { Teleworking, car sharing/car club, cycling, } \\
\text { public transport commuting, avoid short } \\
\text { flights, closer holidays and eco-driving }\end{array}\end{array}$ & $\begin{array}{c}\text { Teleworking, car sharing/car club, pub- } \\
\text { lic transport commuting, avoid short } \\
\text { flights and eco-driving }\end{array}$ & $\begin{array}{c}\text { Carpool commuting, } \\
\text { teleworking and } \\
\text { Housing }\end{array}$ \\
$\begin{array}{l}\text { Less heating/cooling, organic waste } \\
\text { recycling/composting, paper/carton } \\
\text { recycling and plastic/metal/glass recycling }\end{array}$ & $\begin{array}{c}\text { Organic waste recycling/composting, } \\
\text { paper/carton recycling and plastic/- } \\
\text { metal/glass recycling }\end{array}$ & $\begin{array}{c}\text { Paper/carton recycling } \\
\text { and } \\
\text { plastic/metal/glass } \\
\text { recycling }\end{array}$ \\
\hline
\end{tabular}


Conscious profile The conscious adapter is well aware of all the environmental consequences of his/her actions but does not want to give up certain basic needs for this. Instead, he or she is the modern metropolitan role model for environmental consumerism. He or she follows a healthy diet, without unnecessarily wasting any food, does not have a car and uses public transport and rental cars to get around (always applying eco-driving), tries to avoid flying when possible but does not want to give up exotic long-distance holidays. Finally, he or she separates all types of household waste.

Convenient profile The convenient adapter is more or less informed about the environmental impact of his or her actions, but does not want to significantly adapt his/her lifestyle in order to reduce this impact. Instead, he or she adopts some relatively easy forms of green behaviour, such as reducing his or her food waste, carpooling with a colleague to work, applying eco-driving techniques and separating paper and other packaging waste from all other waste.

Combining several behavioural options that are discussed in this study, we can make up to significant mitigation portfolios. Table 6 shows that up to $16.2 \%$ of emissions can be saved when adopting many behavioural options. As this mitigation potential through behavioural action is very significant, we can compare it with the total required mitigation promised by the EU in the Paris Agreement. Translating this agreed promise to cumulative per capita emissions, an equivalent of about 50 tons of carbon per capita has to be mitigated before 2050 compared with the baseline scenario. This is $39.6 \%$ of total emissions in the period 2011-2050 according to the baseline scenario. Figure 2 shows that the carbon reduction per capita due to the adoption of a climate-friendly behavioural profile reaches up to 14 tons of carbon equivalent or 19 tons if the total footprint impact is counted. ${ }^{21}$

An important conclusion to draw from this figure is that significant contributions can be made due to costless behavioural change, up to one third of the total EU mitigation target or over $40 \%$ when the total 'footprint' impact would count. But even modest behavioural change could mitigate 7 tons of carbon per capita, or 5.5 domestic tons accounting for $11 \%$ of the total EU mitigation target. The amount of emission savings however decreases if a climate policy is active, since the GHG intensity of all consumption categories will decrease due to such a policy. Section 1.8 will discuss this interaction in more detail.

One rather strong assumption of the estimates in this section has been that modelled behavioural change will start immediately, from the very first period after the base year, in this case 2015..$^{22}$ Although it is not impossible for any of the behavioural options to start from tomorrow onwards, it might be more realistic to expect a later starting date due to different barriers. Figure 3 therefore gives the total emission savings compared with the baseline scenario dependent on when the individual starts to adopt a behavioural profile. ${ }^{23}$ This figure shows that even when individuals start being conscious about climate change, and act

\footnotetext{
${ }^{21}$ Although the figure seems to give slightly higher percentages, it should not be forgotten to subtract the small increase in emissions due to less biomass use from the total emission reduction. See data inside parenthesis in Fig. 2 caption.

22 Since GCAM runs in 5-year periods and the base year is 2010 , the closest modelling year to the publication of this project is 2015. We are aware that this is effectively in the past, but the idea behind this is that the behavioural option is applied immediately. The 1-2 years of difference have a negligible effect on the total impact of each option.

${ }^{23}$ See Table 11 in Appendix 3 for a detailed table on the emission savings for all behavioural options depending on the adoption year. Note that in case of a radical land use change, as we see with behavioural change in the food sector, we accounted the full land use savings to the year in which the adaptation takes place, even if the new vegetation is not completely grown yet.
} 
Table 6 Overview of GHG emission savings per behavioural profile

\begin{tabular}{llll}
\hline & Total 2011-2050 & $\% \mathrm{CO}_{2}(\mathrm{FFI})^{\mathrm{a}}$ & $\%$ domestic $^{\mathrm{b}}$ \\
\hline Convenient profile & $-5.6 \%$ & 59.4 & 76.4 \\
Conscious profile & $-12.0 \%$ & 35.7 & 71.1 \\
Enthusiastic profile & $-16.2 \%$ & 34.8 & 74.5 \\
\hline
\end{tabular}

aFossil fuel and industry: includes all $\mathrm{CO}_{2}$ emissions related to fossil fuel use but no $\mathrm{CO}_{2}$ emissions from land use change

${ }^{\mathrm{b}}$ Share of emission reductions within EU-27 region

accordingly (on average) around 2025, solely by costless behavioural change they can mitigate $10 \%$ compared with the baseline emissions, which is equal to one fourth of the individuals' share of the total mitigation target in the EU. Such an emission reduction is still significant and could be a more realistic target for most individuals and policymakers than an immediate adoption of the enthusiastic profile.

\subsection{Impact on domestic EU climate policy}

The majority of GHG emission savings due to behavioural change take place in the region itself. As we could see in Table 6 and Fig. 2 in Sect. 3.3, around 75\% of the total emission savings related to the adoption of different behavioural profiles are realised within the EU-27 region. As mentioned in Sect. 2.4, the European Union submitted a nationally determined contribution (NDC) to the Paris Agreement in 2015, committing itself to significant reductions in GHG emissions.

There are various ways in which a climate policy can take form. In Sect. 2.4, we explained that a cap-and-trade policy is assumed in which the determined carbon reductions as promised in the EU NDC are set and the GHG price in the market is variable. Such a price on GHG

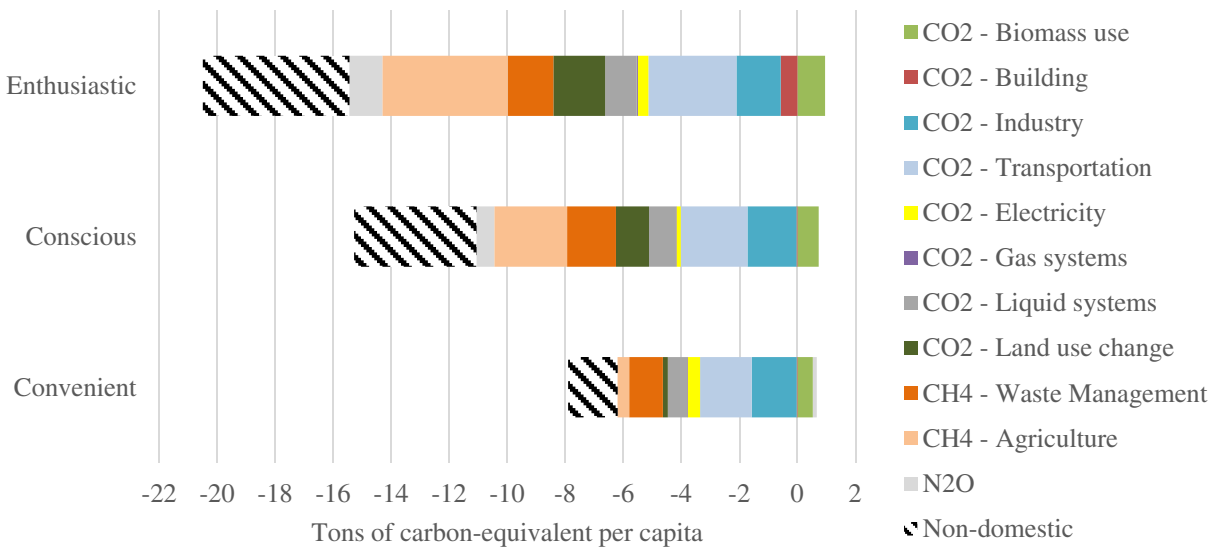

Fig. 2 Per capita GHG emission reduction compared with baseline emissions for the three behavioural profiles, accumulated from 2011 to 2050. Total savings are split between different domestic sectors and savings outside the EU-27 area (The sector 'biomass use' represents the change in biomass use for different end-use sectors. If positive, biomass use has decreased implying that less $\mathrm{CO}_{2}$ has been taken out of the atmosphere. On the other side, this also means that there are less emissions related to burning biomass. This decrease in emissions is distributed over the different end-use sectors. This is the way the GCAM model accounts for biomass emissions) 
Behavioural profile adopted by:

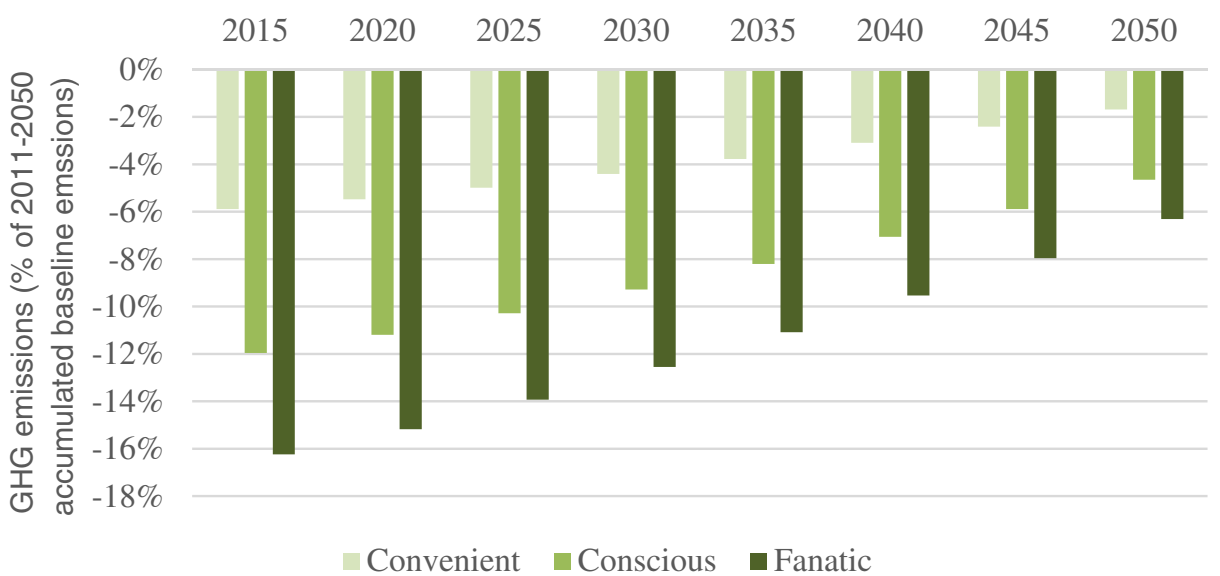

Fig. 3 Avoided GHG emissions per behavioural profile dependent on starting year of behavioural change

gases is expected to impact technology choices such that the necessary GHG emission cap is reached using the least-cost technological options. While there is certainly an overlap between the GHG emission savings due to a cap-and-trade policy and climate-friendly behavioural change, a large part of the GHG emissions that would be abated by adopting one of the behavioural profiles from Sect. 3.3, would be unabated in case of a cap-and-trade climate policy. This is because the sectors that are impacted by the adoption of these profiles are generally the sectors that do not respond strongly to GHG emission prices.

Table 7 shows the impact of climate-friendly behavioural change with and without a capand-trade climate policy on GHG emissions and climate policy costs. It follows from these results that the policy costs related to a climate policy to realise the EU NDC by 2050 could be significantly reduced if the average EU citizen adopted a climate-friendly behavioural profile. Since the GHG emissions abated by behavioural change are among the most expensive to be abated by a climate policy, we can see that the impact of adopting a behavioural profile on policy costs is relatively high (14 to $30 \%$ ), despite the partial overlap between green behaviour and climate policies.

\subsection{Global footprint impact}

All behavioural options in this analysis have been modelled as consumer side preference changes. Thus, all behavioural change is independent from climate policies, and might be adopted due to awareness about climate change as well as monetary, health or animal wellbeing considerations. An important co-benefit of this type of mitigation is that final demand for the polluting good or service has inherently disappeared. In contrast, a carbon tax would simply force demand away by imposing monetary implications, leading to a short to medium term pressure towards consumption of the polluting good or service. In the case of zero or lower carbon taxes in other regions, this pressure will often lead to both industrial and terrestrial carbon leakage ${ }^{24}$ (González-Eguino et al. 2016).

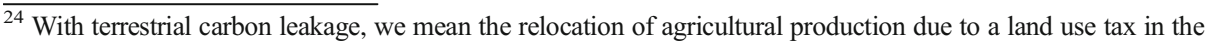
policy region.
} 
Table 7 Regional impact of behavioural change, climate policy, and a combination of both

\begin{tabular}{llll}
\hline Scenario & $\begin{array}{l}\text { Accumulated GHG emission } \\
\text { savings within EU-27 in 2011- } \\
2050^{\mathrm{a}}\end{array}$ & $\begin{array}{l}\text { Total policy costs } \\
2020-2050 \text { rillion } € \\
(2010)\end{array}$ & $\begin{array}{l}\text { Per capita policy costs } \\
2020-2050 €(2010)\end{array}$ \\
\hline $\begin{array}{l}\text { Baseline + convenient } \\
\text { profile }\end{array}$ & $-4.5 \%$ & N/A & N/A \\
$\begin{array}{l}\text { Baseline + conscious } \\
\text { profile }\end{array}$ & $-8.5 \%$ & N/A & N/A \\
$\begin{array}{l}\text { Baseline + enthusiastic } \\
\text { profile }\end{array}$ & $-12.1 \%$ & N/A & N/A \\
$\begin{array}{l}\text { EU NDC } \\
\begin{array}{l}\text { EU NDC + convenient } \\
\text { profile }\end{array}\end{array}$ & $-39.6 \%$ & 1.99 & 3972 \\
$\begin{array}{l}\text { EU NDC + conscious } \quad-39.6 \% \\
\text { profile }\end{array}$ & 1.72 & 3431 \\
$\begin{array}{l}\text { EU NDC + enthusiastic } \\
\text { profile }\end{array}$ & $-39.6 \%$ & 1.54 & 3081 \\
\hline
\end{tabular}

${ }^{\text {a }}$ Percentages with respect to baseline emissions, see Sect. 2.4

Although a limited form of carbon leakage might exist in the case of behavioural change through the depressing effect it could have on global energy and food commodity prices, this effect seems hardly visible in the results (see positive emissions in Fig. 4). In fact, the results indicate that this effect will be more than offset by the reduced footprint emissions that green behaviour has (see negative emissions in Fig. 4). A decreasing demand for food and energy in the EU-27 frees up agricultural land in other regions and avoids emissions related to the mining of energy resources.

Like Bajželj et al. (2014) and Alexander et al. (2015), we found a strong impact of diet changes and food waste reduction on (mainly) global land use change emissions (Fig. 4) and land availability (Fig. 5). Interestingly, as we can see in Fig. 5, the reduction of land footprint by EU consumers would not only prevent forest-, grass-, pasture- and shrub lands to be converted for agricultural use, but also encourage the production of biomass energy due to lower land costs. Consequently, the share of biomass in the global energy mix will grow, crowding out fossil fuels (see Fig. 4).

Finally, we also see a small impact of behavioural change on the emissions related with liquids (oil refining) and gas processing. A lower demand for fossil fuels in the EU saves emissions related with the production of these fuels in other regions. Similarly, we also see a saving in methane emissions, which are mainly due to a reduction in fossil fuel mining.

\subsection{Co-benefits}

Several of the behavioural options discussed have significant co-benefits for either the adopters themselves or society as a whole. Although we did not estimate these co-benefits in this study, they play an important role in the attractiveness to adopt a certain behaviour. Table 8 gives a brief overview of the potential co-benefits that go along with the adoption of behavioural options.

We can conclude from Table 8 that most behavioural options yield monetary co-benefits and also either personal of societal health co-benefits. For example, non-meat food products are generally cheaper than meat products and cycling, carpooling and flight avoiding also 


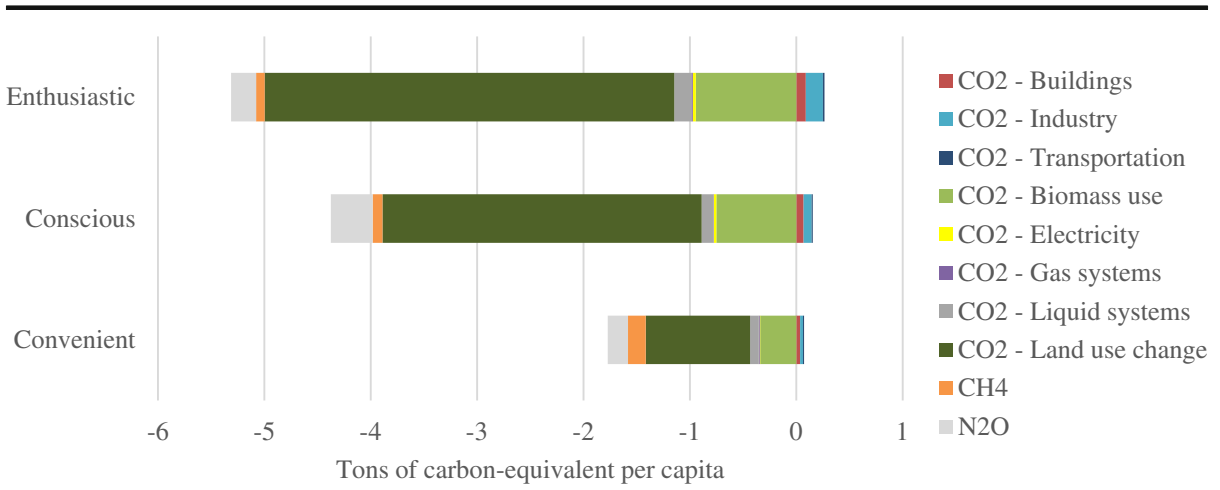

Fig. 4 Footprint impact due to adoption of behavioural change in EU-27 on GHG emissions outside the EU-27, representing in detail the savings within the non-domestic share from Fig. 2 (see Fig. 2 caption for an explanation on the biomass use sector)

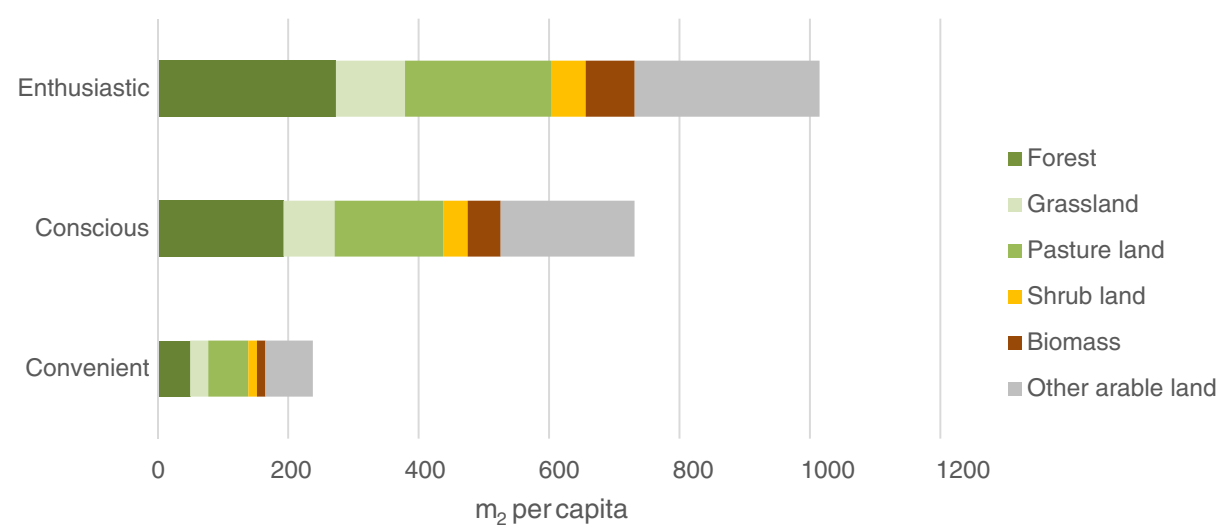

Fig. 5 Per capita amount of avoided cropland due to behavioural change in EU-27, per land use category (average for period 2011-2050)

generally save money just as putting the thermostat to a lower level in winter. Car- sharing and public transport systems could save individuals money as well, depending on the specific carshare programme or public transport operator.

Adopting a healthy diet is by definition good for someone's own health, whereas the adoption of a vegetarian and vegan diet could be good for one's health as well, depending on the exact diet specifications. ${ }^{25}$ Similarly, cycling could be healthy in the sense that it keeps someone fit, but it could simultaneously be unhealthy due to greater respiration of urban air pollution and the increased chance of street accidents (De Hartog et al. 2010), whereas ecodriving could only decrease one's possibility to be involved in a car accident, ${ }^{26}$ improving the health impact for eco-driving on average.

Any option that reduces the amount of toxic gases - such as nitrogen oxides related to transport or ammonia related to animal agriculture - in populated areas improves society's health by doing so. Furthermore, the recycling of different waste streams improves public

${ }^{25}$ A vegan diet with too little protein consumption is for example rather unhealthy.

${ }^{26} \mathrm{http}: / / \mathrm{www} . e c o d r i v e r-p r o j e c t . e u /$ 
Table 8 Expected co-benefits of behavioural options

\begin{tabular}{|c|c|c|c|c|}
\hline \multirow{2}{*}{ Behavioural option: } & \multicolumn{4}{|c|}{ Co-benefits: } \\
\hline & Monetary & Own health & Society health & Animal well-being \\
\hline \multicolumn{5}{|l|}{ Food demand } \\
\hline Healthy diet & $\times$ & $\times$ & $\times$ & $\times$ \\
\hline Vegetarian diet & $\times$ & $\sim$ & $\times$ & $x$ \\
\hline Vegan diet & $\times$ & $\sim$ & $\times$ & $\times$ \\
\hline Food waste reduction & $\times$ & & $\times$ & $x$ \\
\hline \multicolumn{5}{|l|}{ Mobility demand } \\
\hline Public transport commuting & $\sim$ & & $\times$ & \\
\hline Carpool commuting & $\times$ & & $\times$ & \\
\hline Teleworking & $\times$ & & $\times$ & \\
\hline Urban cycling & $\times$ & $\sim$ & $\times$ & \\
\hline Car sharing/car club & $\sim$ & & $\times$ & \\
\hline Avoid short flights & $\times$ & & $\sim$ & \\
\hline Closer holidays & $\times$ & & & \\
\hline Eco-driving & $\times$ & $\times$ & $\times$ & \\
\hline \multicolumn{5}{|l|}{ Housing demand } \\
\hline Reduce heating/cooling & $\times$ & & & \\
\hline Organic waste recycling/composting & & & $\times$ & \\
\hline Paper waste recycling & & & $\times$ & \\
\hline Plastic/metal/glass waste recycling & & & $\times$ & $\times$ \\
\hline
\end{tabular}

' $\times$ ' certain co-benefit, ' $\sim$ ' dependent on specific attributes

health directly if the waste would otherwise have been incinerated, landfilled or disposed to the streets. Each practice release gases that negatively impact public health.

Finally, the reduction of meat consumption, even by a reduction of animal food waste, reduces the number of animals suffering in animal husbandry industries. This is the major reason why people generally adopt a vegetarian or vegan diet. The recycling of plastic waste also improves animal well-being as it prevents microplastics to end up in their food-chain (Derraik 2002).

Apart from these co-benefits, voluntary engagement in pro-environmental behaviour seems to significantly improve someone's subjective well-being according to evidence from the United States (Jacob et al. 2009), Canada (Schmitt et al. 2018), Germany (Welsch and Kühling 2011), Sweden (Kaida and Kaida 2016), Spain (Suárez-Varela et al. 2016), Mexico (Corral-Verdugo et al. 2011) and China (Xiao and Li 2011). For example, using samples from Canada and the USA, Schmitt et al. (2018) confirm significantly positive impact on subjective well-being for 37 out of 39 pro-environmental behaviours, including 9 behaviours of which the potential mitigation effort has been analysed in this study. ${ }^{27}$

Another important conclusion is that it is hard to imagine any negative side-effects related to any of the modelled behavioural options with either monetary or health consequences. ${ }^{28}$ Because of that, the only remaining incentives of why not to adopt these behavioural options

\footnotetext{
${ }^{27}$ The behavioural options from this study that appear to positively influence subjective well-being according to Schmitt et al. (2018) are: Vegetarian diet, Urban cycling, Car sharing / car club, Public transport and Carpool commuting (insignificant impact), Reduce heating / cooling, Organic waste recycling/composting, Paper waste recycling and Plastic/Metal/Glass waste recycling.

${ }^{28}$ Unless, a wrong implementation of the option is applied, such as a vegan diet without protein consumption or a suicidal cycling style.
} 
will be driven by barriers such as costs in terms of time or effort or personal preferences (Fujii 2006; Quimby and Angelique 2011).

\section{Discussion and conclusions}

\subsection{Discussion}

Generally, as the limited studies in literature have shown, a change towards climate-friendly behaviour by citizens can reduce GHG emissions substantially. Apart from that, many of these options usually have negative monetary costs and in some cases imply significant health cobenefits. This study analyses the impacts of preference changes that could contribute to the climate change mitigation portfolio, but for the normative question on how to change these preferences, we have to rely on the extensive amount of existing literature on this topic.

There seem to be several psychological barriers to behavioural change (Lorenzoni et al. 2007; Whitmarsh 2009; Quimby and Angelique 2011), even if the individual's welfare or subjective well-being effect is positive (Gifford 2011; Schmitt et al. 2018). Being aware of the dangers of climate change helps the adoption of pro-environmental behaviour (PEB) but certainly not guarantees it (Semenza et al., 2008; Ohe and Ikeda 2005; Ozaki 2011; Lin 2013; Masud et al. 2015). Moreover, literature confirms that the adoption of PEBs has, apart from sociodemographic variables, a lot to do with environmental attitudes. These attitudes are apart from influenced by environmental awareness and risk perception and also by personal and social values such as social justice, community, frugality and personal integrity (Poortinga et al. 2004; Fujii 2006; Gadenne et al. 2011; Hards 2011; Howell 2013).

In order to boost the adoption of PEBs by citizens, public policy might be necessary. Since we are focusing in this study on costless behavioural change due to preference changes, it is a matter of discussion if taxation should be a way to convince consumers to change their behaviour. Recent literature indicates that taxes on unhealthy food products containing a certain amount of fat or sugar, as well as subsidies for healthy food products, can effectively mitigate GHG emissions and improve health (Thow et al. 2014; Gustavsen and Rickertsen 2013; Abadie et al. 2016). However, such unhealthy food taxes do not necessarily increase consumer welfare (Lusk and Schroeter 2012) if the consumer inherently would have preferred the taxed product and can therefore lead to GHG emissions leakage to bordering regions. Also, different income groups will respond differently to such taxes and they can finally have regressive distributional impacts (García-Muros et al. 2017; Gustavsen and Rickertsen 2013). In the end, being taxed away from the consumption of a certain good is not the same as a preference change.

Alternatively, consumers could be inherently convinced to change their preferences, for example, by consistent public awareness campaigns about climate change (Fujii 2006; Lorenzoni et al. 2007). According to Howell (2013), instead of providing simple recommendations to combat climate change, such campaigns should provide a more holistic view of a lower-carbon future as it increases intrinsic motivation to adopt and sustain PEB. According to O'Neill and Nicholson-Cole (2009), it is important that such campaigns are not fearful, but rather link to individuals' everyday emotions and concerns in the context of climate change. In terms of mitigation, a way of doing this is by relating climate change to local environmental issues and personal concerns, emphasising the additional benefits of PEBs (Lorenzoni et al. 2007). For example, persuasive campaigns against the consumption of meat have been realised 
by animal protection and food-focused NGOs. According to Laestadius et al. (2014), environmental NGOs have however shown little incentives to campaign for a reduction in meat consumption as they appeared to be reluctant to mount campaigns explicitly encouraging personal behaviour change of any type. It makes sense that, when significant co-benefits are related with a certain type of behaviour (see Sect. 3.6), the willingness of consumers to adopt this behaviour will increase. In any case, whether there are significant co-benefits involved or not, public awareness about climate change could be improved (Sheppard 2005; Moser 2010).

Finally, voluntary mitigation by the public to adjust lifestyles can be maximised only if the general public and other stakeholders see the benefits of such sacrifices, which requires legislative and regulatory measures from industry, commerce, and government. Ultimately, effective mitigation of climate change requires both structural and behavioural changes towards a more sustainable society (Semenza et al. 2008). The results from this study confirm that costless behavioural change can potentially contribute to a significant part of the total necessary climate change mitigation efforts and that the majority of mitigation efforts still have to come from structural transformation in the energy system. Therefore, it is important that behavioural change appears in future energy and climate scenarios for policymakers, so that its potential can be assessed in combination with different technology assumptions (Samadi et al. 2017).

\subsection{Conclusions}

This study explores the mitigation potential of various types of behavioural actions in food, mobility and housing demand, and sketches different green consumption profiles. Unlike Dietz et al. (2009), the behavioural options considered do not require investments in new or cleaner technologies. Therefore, there will be no need for upfront investments to be made by the consumer, which is an important barrier for making energy-saving investments (Costanzo et al. 1986; Gadenne et al. 2011). From an analytic point of view, the absence of technology requirements allows us to compare and add these results to mitigation portfolios that are based on the adoption of cleaner technologies, with few overlapping emission savings.

A thorough analysis of the results show that costless behavioural change can contribute, if adopted immediately, up to one third of the GHG emission target of the EU by 2050 or up to $40 \%$ if all footprint emissions would be counted. But even a more convenient way of behavioural change as well as an average environmentally conscious living style adopted from around 2025 could contribute to respectively 14 and $25 \%$ of the total mitigation effort. The use of a global integrated assessment model (GCAM) allows also to measure the international aspects of domestic behavioural changes. Interestingly, environmentally friendly behavioural change reduces emissions and land use change in other regions, which means that the positive footprint effect dominates the negative 'carbon leakage' effect. In contrast, forcing environmentally friendly behaviour with a GHG emission tax typically yields carbon leakage in other regions (González-Eguino et al., 2016).

However, using an IAM to assess the impacts of behavioural change is subject to several limitations, such as methodological limitations, the limited representation of lifestyle changes in IAMs and general limitations in integrated assessment (van Sluisveld et al. 2016, pp. 316317). For example, the inability to model the rebound effects of potential monetary savings of green behaviour with the model forced us to assume the monetary savings to be spent GHGneutral (see Sect. 3.1). However, such rebound effects can reduce the total effectiveness of green behaviour up to $34 \%$ for housing and mobility options (Druckman et al. 2011) and 49\% 
for food options (Grabs 2015). These limitations could be overcome in the future with the support of other modelling tools such as agent-based models and computable general equilibrium modes.

The co-benefits of environmentally friendly behaviour can be in some cases significant and, therefore, could also encourage citizens to adopt this behaviour. There are a lot of potential gains from following a more sustainable lifestyle for EU citizens. Moving to more sustainable lifestyles in developed regions might simultaneously yield more sustainable lifestyles in developing regions by giving a better example (Lange and Meier 2009). Surely in the case of behavioural options that imply significant co-benefits for the adopter, 'leapfrogging' of sustainable lifestyle features might be a realistic climate mitigation strategy for developing regions (Schäfer et al. 2011). A good example of behavioural change from a developed nation could therefore be of relevant value for future emissions from developing nations.

To conclude, policymakers predominantly look at taxes and subsidies in order to provide technological solutions to reach their climate targets. As follows from this analysis, behavioural effects can play a significant role in climate change mitigation portfolio and this potential should therefore be reflected in scenario studies aiming to provide comprehensive advice to policymakers (Samadi et al. 2017). More specifically, the results from this study imply that policymakers should put more effort in education and awareness programs in order to promote green behaviour by citizens, where it is important to focus on a more holistic view of a low-carbon future (Howell 2013) as well as individuals' everyday emotions and concerns in the context of climate change (O’Neill and Nicholson-Cole 2009), for example, by linking PEB with the additional benefits that come along with them. The policy costs of such measures are usually low compared with the implementation of taxes and subsidies and, in addition, they often lead to significant public co-benefits in terms of health, land use and overall well-being.

Acknowledgements The authors thank Hector Pollitt and Francis Johnson for valuable comments and Ed Dearnley for a language check. This study received funding from the European Union's Horizon 2020 research and innovation programme under grant agreement no. 642260 (TRANSrisk project). Mikel González-Eguino and Iñaki Arto acknowledge financial support from the Ministry of Economy and Competitiveness of Spain (ECO2015-68023) and the Basque Government (IT-799-13). All data and model outputs of this article are available upon request to Dirk-Jan van de Ven (dj.vandeven@bc3research.org).

\section{Compliance with ethical standards}

Conflict of Interest The authors declare that they have no conflict of interest.

\section{Appendix 1: Background modelling of mobility and housing options}

\section{Public transport commuting}

In the base year (2010), around 20.7 and $17.9 \%$ of total passenger kilometres in respectively EU-15 and EU-12 were due to commuting between home and work. Of this commuting transport demand, only $15.1 \%$ in EU-15 and $29.3 \%$ in EU-12 was met by public transport services (EC 2010a). 


\section{Carpool commuting}

In the base year, car trips yielded around $76.2 \%$ of the total commuting passenger kilometres in EU-15, while around 58\% in EU-12. Car load factors ${ }^{29}$ for commuting transport were 1.19 in EU-15 and 1.87 in EU-12, whereas car load factors for total car transport were 1.65 and 2, respectively (EC 2010a). Assuming a car load factor for commuting transport of 2 while respecting the share of commuting kilometres in total passenger kilometres $(20.7$ and $17.9 \%$ in EU-15 and EU-12 respectively), we increased the overall load factor for all four-wheel driven transport modes to 1.85 in EU-15 and 2.05 in EU-12 to model this behavioural option. Finally, in order to model only the emission savings as a result of this behavioural change, we cancelled out any kind of price elastic behaviour in favour of car transport following to this adjustment.

\section{Teleworking}

Since the commuting share of passenger transport is 20.7 and $17.9 \%$ in the EU-15 and EU-12, respectively (see previous options), we reduced total passenger transport demand by $4.14 \%$ in EU-15 and $3.6 \%$ in EU-12.

\section{Urban cycling}

According to EC (2010a), slow mode transport (walking and cycling) accounts for $18.9 \%$ of total urban passenger transport in the Netherlands in 2010, while total urban passenger transport accounts for about $29 \%$ of all passenger transport. Assuming the same percentage of slow mode transport in urban areas for the whole of EU-27, this comes down to an average share of $5.4 \%$ of total passenger transport that would be met by walking and cycling together. GCAM reports the share of walking to account for $1.9 \%$ of passenger transport in EU-27 in 2010, so we assume that the potential share of bicycles in total EU-27 passenger demand will be around $3.5 \%$. Note that while we keep the cycling share to $3.5 \%$ during all periods for this behavioural option, the walking share is subject to market competition (and decreases rapidly due to an increasing cost of travel time, see also, Mishra et al. 2013).

\section{Car sharing/car clubs: methods and assumptions}

The calculation used to make assumptions for both emission-saving effects is as following. Based on a ratio of 27 members per shared car in the USA, the Trasportation Research Board (2005) reports an amount of 14.9 cars to be taken off the road for every car-club vehicle. Applying the ratio of 20 members per shared car in Europe, the estimate for Europe would be 11 cars per car-club vehicle. Correcting this estimate by the $40 \%$ reduction in vehicle kilometres of car-share members compared with private vehicle owners, this ratio comes down to $11 \times 0.6=6.62$. Finally, Chen and Kockelman (2015) state that the average privately owned new vehicle is replaced after approximately 6 years, whereas commercial car-club

${ }^{29}$ The average amount of people carried by one car. 
operations replace cars every 2 to 3 years due to more vehicle kilometres and faster wear and tear (Mont 2004). Assuming that the wear and tear to the car and the remaining life time is the same for privately sold second hand cars and those sold by car-sharing companies, we can state that a privately owned vehicle has two to three times the lifetime of a car-club vehicle. Applying a lifetime ratio of $2.5,{ }^{30}$ this means that every car-sharing vehicle takes 6.62 / $2.5=2.65$ vehicles off the production line when assuming that there is no reduction in car use between car owners and car sharers. Furthermore, we assume an energy consumption related to car manufacture of $30 \mathrm{GJ}^{\text {vehicle }}{ }^{-1}$ (Sullivan and Wang 2010) and a growing demand for cars proportionally to the growing demand for passenger kilometres in both EU-15 and EU-12. See Table 9 for a summary on the assumptions made for modelling the impacts of car sharing.

\section{Avoid short flights}

We summed all the passenger kilometres on national flights within EU-27 member states ${ }^{31}$ and all flights to neighbouring countries (multiplied by half if at least one of the partner countries is a large country such as Germany, France, UK, Italy or $\mathrm{Spain}^{32}$ ) to have a rough estimate of the potentially avoidable flights. We found that about $25 \%$ of all passenger kilometres on intra-EU flights are avoidable by these standards, and implicitly assume that it remains $25 \%$ until 2050.

As an alternative to flying for medium distance trips, we modelled a new category with four possible travel alternatives: coach, train, high-speed-rail and carpooling. Although we copied these transport modes from the original GCAM model, we assume significantly higher speeds for long distance bus, train and car transport (80,100 and 100, respectively) and a higher load factor for cars. ${ }^{33}$ Initially, each of these alternatives takes an equal share of the passenger kilometres to be replaced, but the mix between technologies is subject to mode competition as in other GCAM sectors.

\section{Closer holidays}

A rough analysis of Eurostat data on intercontinental passenger kilometres from EU-15 and EU-12 shows that respectively 85 and $91.5 \%$ of passenger kilometres are for leisure purposes and that the average intercontinental leisure trip by EU-15 and EU-12 consumers is respectively about 5900 and $2680 \mathrm{~km}$ long. We implicitly assume that these estimates will not change until 2050.

\footnotetext{
${ }^{30}$ This lifetime ratio is also applied to the assumed vehicle lifetime in GCAM (decreasing from 25 to 10 years), resulting in an increasing average fuel efficiency of cars.

${ }^{31}$ Although some countries like Germany, France, Spain, Italy and the UK have large distances from one outer point to the other outer point, there are usually good train and bus connections available within the country borders.

32 That is, we consider a flight from Brussels to Paris avoidable but a flight from Brussels to Marseille unavoidable. By dividing the number of flights between Belgium and France by two, we hope to have a proper estimate of avoidable flights.

${ }^{33}$ We used a load-factor of 2.8, which is the average load factor of trips with BlaBlaCar, one of Europe's biggest carpooling platforms for long distance trips: https:/www.blablacar.co.uk/about-us
} 
Table 9 Assumptions made to model car-sharing impact

\begin{tabular}{|c|c|c|c|}
\hline Parameter & Source & Value & Multiplier \\
\hline Vehicles replaced per car-club vehicle in the USA & $\begin{array}{l}\text { Transportation Research } \\
\text { Board (2005) }\end{array}$ & 14.9 & \\
\hline Correction for members per car-club vehicle in Europe & $\begin{array}{l}\text { Transportation Research } \\
\text { Board (2005) }\end{array}$ & & $20 / 27$ \\
\hline $\begin{array}{l}\text { Correction for reduced vehicle kilometres by car sharers } \\
\text { compared with car owners }\end{array}$ & $\begin{array}{l}\text { Transportation Research } \\
\text { Board (2005) }\end{array}$ & & 0.6 \\
\hline $\begin{array}{l}\text { Shared vehicle lifetime compared with privately owned } \\
\text { vehicle lifetime }^{\mathrm{a}}\end{array}$ & $\begin{array}{l}\text { Chen and Kockelman (2015) } \\
\text { and Mont (2004) }\end{array}$ & & 0.4 \\
\hline $\begin{array}{l}\text { Reduction of vehicle production for every car-sharing } \\
\text { vehicle }\end{array}$ & & 2.65 & \\
\hline Manufacturing energy use per vehicle & Sullivan and Wang (2010) & $30 \mathrm{GJ}$ & \\
\hline $\begin{array}{l}\text { Amount of passenger car sales in EU-27 in } 2010 \text { (base } \\
\text { year) }\end{array}$ & Oica.net & $\begin{array}{c}13.8 \\
\text { mil- } \\
\text { lion }\end{array}$ & \\
\hline
\end{tabular}

${ }^{\text {a }}$ See footnote 30

\section{Eco-driving}

According to the ecoDriver project website, the EU initiative that started in 2010 to promote this fuel-efficient driving style, the long-term fuel reduction due to eco-driving is estimated to be $5 \% .{ }^{34}$ Following this number, we modelled this behavioural option by increasing the efficiency of all four-wheel light duty vehicles by $5 \%$ from 2015 onwards.

\section{Reduce heating and cooling}

To model the reduced usage of heating, we simply modified the residential HDD input (heating degree days) from 4920 to 4625 in EU-15 and from 6311 to 5930 in EU-12, a change that reduces the need for heating in winter by about $1{ }^{\circ} \mathrm{C}$. Similarly, we changed the residential cooling degree days (CDD) input from 373 to 328 in EU-15 and from 343 to 302 in EU-12 to model a reduced use of air-conditioning in summer.

\section{Appendix 2: Modelling and assumptions of GCAM waste module}

To model the impacts of waste recycling by consumers, we focus on the three main streams of consumer waste: organic waste, paper/carton waste and non-paper packaging waste (consisting of mainly plastics, metals and glass). In most EU member states, it is possible for households to effectively recycle these types of waste by separating them. For modelling simplicity, we will assume from now that $100 \%$ of separated waste actually will be recycled ( $8 \%$ actually ended up between mixed waste in 2010, predominantly separated organic waste in landfills) and that $0 \%$ of mixed waste will be recycled (8\% of mixed waste was actually recycled in 2010). See Fig. 6 for an overview of all waste and recycling streams in EU-27 in 2010.

$\overline{{ }^{34} \text { http://www.ecodriver-project.eu/ }}$ 


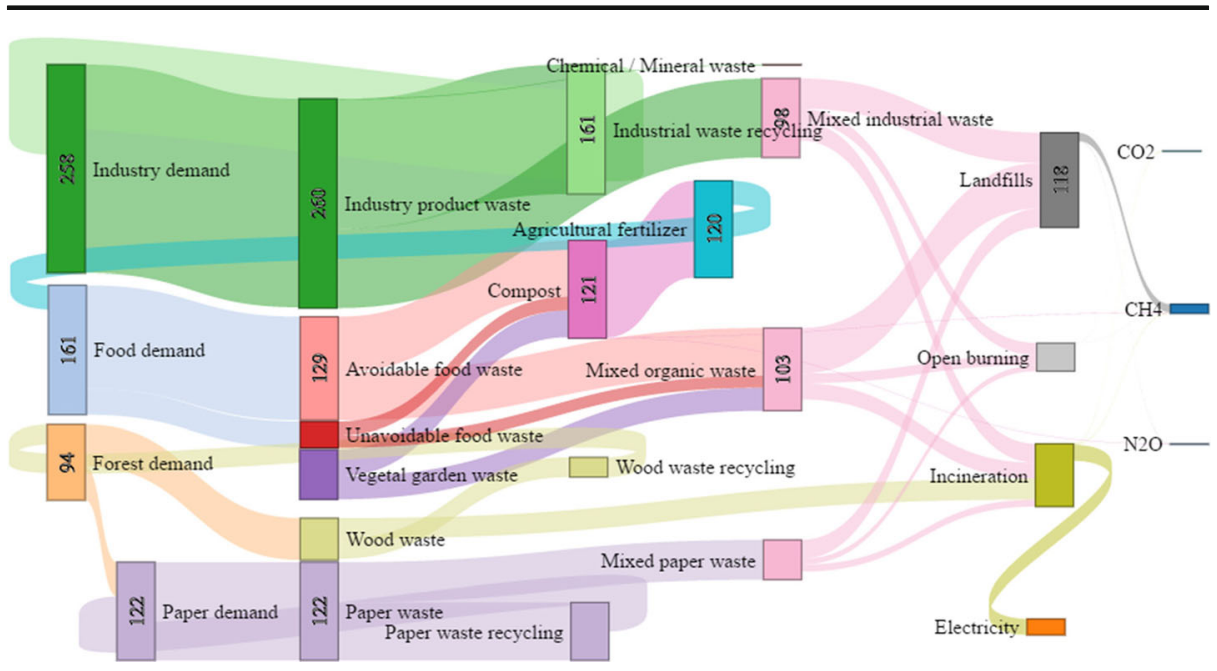

Fig. 6 EU-27 waste and recycling streams in 2010 in million tonnes (based on EuroStat data)

Since $66 \%$ of household waste ended up between mixed waste in 2010 , it is hard to determine the contents of these waste streams. Since we need to know the contents to model the potential emission reductions, we have to make an estimation of these contents. To do so, we looked at the best practice example of waste separation in Europe to gain information about the average household waste streams. According to GAIA (2012), European best example is a door-to-door waste collection program in Usurbil, Hernani and Oiartzun in the province of Gipuzkoa, Basque Country, Spain. The three towns together represented 33,628 citizens with a GDP per capita level close to the EU-27 average. Except for the $20 \%$ of waste that was collected from street bins and local street cleaning services, all household waste in these villages was separately collected. The household waste in these villages consisted of $46.8 \%$ organic waste (of which $33.8 \%$ food and $13 \%$ garden waste), $18.3 \%$ paper/carton waste, $32.3 \%$ industrial packaging waste (including $14.1 \%$ glass and $15.2 \%$ plastic and metal) and $2.6 \%$ other waste, such as chemicals or minerals

Since all EU-27 member states have a different waste collection scheme with regionally different priorities, we have multiplied the household waste composition as assumed above to the waste totals in every member state and have deducted the separated waste streams from these assumed waste streams. The remaining waste (i.e. the composition after deducting the separated waste streams per member state) is assumed to be the composition of waste within the mixed waste stream. On an EU-27 level, we find $45.6 \%$ of all mixed household waste to be organic, $13.6 \%$ to be paper/ carton, $33 \%$ to be non-paper packaging waste and a remainder of $7.8 \%$ to be mineral or chemical waste (which we leave out of the model).

For the services and industrial sector (accounting for nearly one third of all mixed waste), waste has traditionally been much better separated. We therefore assume the same mixture of separated waste to hold for the limited amount of mixed waste streams from these sectors. Finally, we also find that about one fifth of the mixed waste in the waste collection industry. This is intentionally separated waste that has a degree of mixture too high to be recycled. Here we simply assume the average assumed waste composition as in the other $80 \%$ of mixed waste. The final assumed mixed waste contents in EU-27 are assumed to be $34.3 \%$ organic 
Table 10 Assumed unavoidable waste streams from different food categories (\% of total weight)

\begin{tabular}{llll}
\hline Cereals & $2.22 \%$ & Meat & $13.63 \%$ \\
\hline Oilseeds and pulses & $3.05 \%$ & Fish and seafood products & $23.44 \%$ \\
Fruits and vegetables & $15.51 \%$ & Dairy & $0.46 \%$ \\
Rice (Oryza sativa) & $1.67 \%$ & Coffee (Coffea) and tea (Thea sinensis) & $11.06 \%$ \\
Root Tubers & $2.08 \%$ & & \\
\hline
\end{tabular}

Source: Comparison between Ventour (2008) and FAO (2011) and van Westerhoven (2013a) for coffee and tea

waste, $15.4 \%$ paper/carton waste, $31.2 \%$ non-paper packaging waste and $19.1 \%$ other waste (mainly mineral). Note that we only modelled the non-household sectors to have a full picture on all waste streams. All the behavioural options do apply to household waste only.

In total, $89 \%$ of all mixed waste in EU-27 was treated within the area, ${ }^{35}$ with the majority being landfilled (in some cases with methane recovery for biogas production). However, there is an important trend going on in Germany, the Benelux and Scandinavia to incinerate mixed waste, either with or without energy recovery. In the baseline estimates, we assume that open burning and unmanaged landfilling of waste will be phased out linearly until 2050 and also managed landfilling will be phased out linearly until 2100, following Directive 2008/98/EC on waste management.

For the total emissions from landfilling, we used data from the European Environment Agency $(E E A)^{36}$ on landfill emissions on managed and unmanaged landfill sites. Following the IPCC guidelines (IPCC 2006), unmanaged landfill sites have on average $40 \%$ less emissions per unit of waste compared with managed landfills. ${ }^{37}$ For modelling simplicity, we assume that all landfill emissions in one period are coming from waste that is landfilled in the same period. To fit our modelled waste streams (stemming from EuroStat data) with the EEA landfill emissions data, we use the methane yields per type of waste stream from EPA (2015). Following the IPCC guidelines, we do not model $\mathrm{CO}_{2}$ emissions from municipal waste management.

\section{Organic waste}

Organic waste consists of both food waste and garden waste. Since we have modelled the assumed amount of food waste in EU-27, we assume that all other organic household waste consists of garden waste (the relative share of garden waste is in line with the distribution in our case example as explained in the start of this Appendix). From 2010 onwards, we assume per capita garden waste to remain constant over time. Food waste consists of unavoidable food waste (which is a by-product of food consumption, predominantly skins and peels of fruits and vegetables, carcasses of pork and chicken, coffee and tea disposals) and avoidable food waste from the production, distribution and consumption of food. We estimated the unavoidable waste stream by GCAM food category by connecting the share of unavoidable waste compared with avoidable waste as reported by Ventour

\footnotetext{
${ }^{35}$ With the other $11 \%$ being either exported or simply lost out of sight

$36 \mathrm{http} / / / w w w . e e a . e u r o p a . e u / d a t a-a n d-m a p s / d a t a / d a t a-v i e w e r s / g r e e n h o u s e-g a s e s-v i e w e r$

37 The reason that unmanaged landfills are assumed to yield less $\mathrm{CH} 4$ emissions is based on the assumption that these are less dense and more widespread (open garbage field) than managed landfills, such that there is less anaerobic degradation of biogenic sources. Obviously these unmanaged garbage fields have other negative side effects on landscapes and potentially health.
} 
(2008) with our FAO's's (2011) estimates of avoidable food waste by food category. Estimates for unavoidable coffee and tea waste streams (NonFood-MiscCrop) come from van Westerhoven (2013a). See the assumed estimates in Table 10.

Landfilling of organic waste results in large amounts of methane due to the anaerobic decomposition of organic materials. These are responsible for $2.75 \%$ of total GHG emissions in EU-27 in 2010. When incinerated, there will be no methane emissions from organic waste but there will be $\mathrm{CO}_{2}$ emissions, which have a significantly lower warming potential. ${ }^{38}$ The energy density of organic waste, however, is very low, so energy recovery from incineration is not very productive. Finally, the preferred treatment for organic waste is to compost it using anaerobic digestion, creating both biogas and a valuable organic fertiliser replacing mineral fertilisers and returning about $15 \%$ of the organic carbon contents back into the soil. This is a form of carbon sequestration (IPCC 2006). Some methane emissions are released in the composting process, but these are limited compared with the methane released with landfilling. In the same way as landfill emissions, we linked data from EEA on composting emissions with Eurostat data on total tonnes composted to estimate the methane and nitrous oxide emissions per unit of food and garden waste composted. Finally, we used estimates from Boldrin et al. (2010) and Zero Waste Europe (2015) to estimate the total carbon and nitrogen content of both food and garden waste.

\section{Paper/carton waste}

We have separated paper waste, since nearly every EU member state offers the possibility to recycle paper and carton waste. Since paper products are made from pulp, which is obtained from forest products, the GCAM model will be helpful in calculating the emissions related to paper waste recycling. Like food and garden waste, paper waste is organic and therefore leads to methane emissions when landfilled. However, the rate in which one ton of paper waste produces methane is only about one fourth compared with that of food waste (EPA 2015). When incinerated, paper products can yield significant energy recovery due to an energy density that is more than twice that of food and garden waste. Finally, recycling of paper waste leads to significant GHG savings: producing new paper out of recycled paper reduces the amount of energy needed for paper production by $40 \%$ (EIA 2006). However, since about four fifth of this saved energy comes from biomass (black liquor) due to the high amount of wood waste in these production locations (Table 17 in AF\&PA 2009), paper production from pulp consumes the majority of the biomass energy in the EU-27 energy mix for industrial products.

\section{Plastic/metal/glass waste}

Although industrial products such as plastic, metal and glass do not emit GHG emissions when landfilled, they do emit other pollutants, which are currently not modelled within GCAM. These pollutants are also emitted when incinerated, along with $\mathrm{CO}_{2}$. Glass and metal waste might also lead to health damages or complicate the whole waste collection procedure by cutting into garbage bags due to their sharp edges. Incineration with energy recovery from

\footnotetext{
${ }^{38}$ Since food waste is a renewable source of (potential) energy, $\mathrm{CO} 2$ emissions resulting from food waste management are not counted by the IPCC standards. CH4 emissions due to landfilling are counted, as these would not have been released in a natural situation where the food would degrade aerobically.
} 
predominantly plastic waste is interesting due to its high energy density: around $50 \%$ higher than paper waste and four times higher than food and garden waste. Plastic, metal and glass waste however is most valuable when recycled: compared with producing new products, using recycled plastic, metal or glass reduces industrial energy use by 70, 60-95 and 5-30\%, respectively (the Economist 2007). Given the average mixed waste composition in the EU27 , we have estimated that the average tonne of recycled industrial products saves about $30 \%$ of industrial energy compared with making the same final industrial products from virgin material (Zero Waste Europe 2015). It is important to note is that the majority of savings comes from recycling metal waste, which saves 60 to $95 \%$ (for aluminium) compared with making these products from virgin materials.

\section{Appendix 3: Sensivity analysis based on starting year of behavioural change}

Table 11 Avoided GHG emissions per behavioural option or profile dependent on starting year of behavioural change

\begin{tabular}{|c|c|c|c|c|c|c|c|c|}
\hline \multirow[t]{2}{*}{ Behavioural option } & \multicolumn{8}{|c|}{ Total avoided emissions compared with baseline if behaviour is adopted by year ${ }^{\mathrm{a}}$} \\
\hline & 2015 & 2020 & 2025 & 2030 & 2035 & 2040 & 2045 & 2050 \\
\hline \multicolumn{9}{|l|}{ Food demand: } \\
\hline Vegan diet & $-8.18 \%$ & $-7.79 \%$ & $-7.33 \%$ & $-6.84 \%$ & $-6.32 \%$ & $-5.77 \%$ & $-5.21 \%$ & $-4.62 \%$ \\
\hline Vegetarian diet & $-6.99 \%$ & $-6.70 \%$ & $-6.37 \%$ & $-6.03 \%$ & $-5.66 \%$ & $-5.27 \%$ & $-4.87 \%$ & $-4.45 \%$ \\
\hline Healthy diet & $-5.27 \%$ & $-5.01 \%$ & $-4.73 \%$ & $-4.43 \%$ & $-4.11 \%$ & $-3.77 \%$ & $-3.43 \%$ & $-3.06 \%$ \\
\hline $\begin{array}{l}\text { Food waste } \\
\text { reduction }\end{array}$ & $-2.38 \%$ & $-2.24 \%$ & $-2.09 \%$ & $-1.93 \%$ & $-1.77 \%$ & $-1.60 \%$ & $-1.43 \%$ & $-1.26 \%$ \\
\hline \multicolumn{9}{|l|}{ Mobility demand } \\
\hline $\begin{array}{l}\text { Public transport } \\
\text { commuting }\end{array}$ & $-0.73 \%$ & $-0.65 \%$ & $-0.59 \%$ & $-0.51 \%$ & $-0.42 \%$ & $-0.32 \%$ & $-0.23 \%$ & $-0.12 \%$ \\
\hline Carpool commuting & $-1.16 \%$ & $-1.12 \%$ & $-1.04 \%$ & $-0.91 \%$ & $-0.74 \%$ & $-0.56 \%$ & $-0.39 \%$ & $-0.20 \%$ \\
\hline Teleworking & $-0.25 \%$ & $-0.23 \%$ & $-0.21 \%$ & $-0.18 \%$ & $-0.15 \%$ & $-0.12 \%$ & $-0.09 \%$ & $-0.05 \%$ \\
\hline Urban cycling & $-0.60 \%$ & $-0.52 \%$ & $-0.46 \%$ & $-0.39 \%$ & $-0.32 \%$ & $-0.25 \%$ & $-0.17 \%$ & $-0.09 \%$ \\
\hline Car sharing/car club & $-1.06 \%$ & $-1.06 \%$ & $-0.96 \%$ & $-0.84 \%$ & $-0.68 \%$ & $-0.51 \%$ & $-0.35 \%$ & $-0.18 \%$ \\
\hline Avoid short flights & $-0.47 \%$ & $-0.42 \%$ & $-0.39 \%$ & $-0.34 \%$ & $-0.28 \%$ & $-0.22 \%$ & $-0.16 \%$ & $-0.08 \%$ \\
\hline Closer holidays & $-0.49 \%$ & $-0.43 \%$ & $-0.38 \%$ & $-0.33 \%$ & $-0.27 \%$ & $-0.21 \%$ & $-0.15 \%$ & $-0.08 \%$ \\
\hline Eco-driving & $-0.59 \%$ & $-0.58 \%$ & $-0.54 \%$ & $-0.47 \%$ & $-0.39 \%$ & $-0.29 \%$ & $-0.20 \%$ & $-0.10 \%$ \\
\hline \multicolumn{9}{|l|}{ Housing demand } \\
\hline $\begin{array}{l}\text { Reduce } \\
\text { heating/cooling }\end{array}$ & $-0.60 \%$ & $-0.52 \%$ & $-0.44 \%$ & $-0.37 \%$ & $-0.30 \%$ & $-0.22 \%$ & $-0.15 \%$ & $-0.08 \%$ \\
\hline $\begin{array}{l}\text { Organic waste } \\
\text { recycling/ } \\
\text { composting }\end{array}$ & $-1.09 \%$ & $-0.93 \%$ & $-0.80 \%$ & $-0.67 \%$ & $-0.53 \%$ & $-0.40 \%$ & $-0.27 \%$ & $-0.13 \%$ \\
\hline $\begin{array}{l}\text { Paper waste } \\
\text { recycling }\end{array}$ & $-0.56 \%$ & $-0.54 \%$ & $-0.47 \%$ & $-0.41 \%$ & $-0.33 \%$ & $-0.25 \%$ & $-0.18 \%$ & $-0.09 \%$ \\
\hline $\begin{array}{c}\text { Plastic/metal/glass } \\
\text { waste recycling }\end{array}$ & $-1.66 \%$ & $-1.46 \%$ & $-1.27 \%$ & $-1.08 \%$ & $-0.87 \%$ & $-0.66 \%$ & $-0.46 \%$ & $-0.23 \%$ \\
\hline \multicolumn{9}{|l|}{ Behavioural profiles } \\
\hline Convenient & $-5.89 \%$ & $-5.48 \%$ & $-4.99 \%$ & $-4.41 \%$ & $-3.77 \%$ & $-3.09 \%$ & $-2.41 \%$ & $-1.68 \%$ \\
\hline Conscious & $-11.96 \%$ & $-11.19 \%$ & $-10.28 \%$ & $-9.28 \%$ & $-8.21 \%$ & $-7.06 \%$ & $-5.89 \%$ & $-4.65 \%$ \\
\hline Enthusiastic & $-16.24 \%$ & $-15.18 \%$ & $-13.93 \%$ & $-12.55 \%$ & $-11.08 \%$ & $-9.54 \%$ & $-7.96 \%$ & $-6.31 \%$ \\
\hline
\end{tabular}

${ }^{a}$ In the case of land use change emissions, all emission reductions are counted to the year the behavioural change takes place, also if the new vegetation is not completely grown yet 


\section{References}

Abadie LM, Galarraga I, Milford AB, Gustavsen GW (2016) Using food taxes and subsidies to achieve emission reduction targets in Norway. J Clean Prod 134:280-297

AF\&PA (2009) 2008 Statistical summary of paper, Paperboard and Wood Pulp. American Forest \& Paper Association, Washington

Alexander P, Rounsevell MD, Dislich C, Dodson JR, Engström K, Moran D (2015) Drivers for global agricultural land use change: the nexus of diet, population, yield and bioenergy. Glob Environ Chang 35: $138-147$

American Heart Association (2014) The American Heart Association's Diet and Lifestyle Recommendations www.heart.org/HEARTORG/GettingHealthy/NutritionCenter/HealthyEating/The-American-HeartAssociations-Diet-and-Lifestyle-Recommendations UCM 305855 Article.jsp

Arto I, Capellán-Pérez I, Lago R, Bueno G, Bermejo R (2016) The energy requirements of a developed world. Energy Sustain Dev 33:1-13

Arto I, Genty A, Rueda-Cantuche JM, Villanueva A, Andreoni V (2012) Global resources use and pollution: vol. I, production, consumption and trade (1995-2008), JRC scientific and policy reports. European Commission Joint Research Centre (IPTS), Luxembourg

Autio M, Heiskanen E, Heinonen V (2009) Narratives of 'green' consumers - the antihero, the environmental hero and the anarchist. J Consum Behav 8:40-53

Bajželj B, Richards KS, Allwood JM, Smith P, Dennis JS, Curmi E, Gilligan CA (2014) Importance of fooddemand management for climate mitigation. Nat Clim Chang 4(10):924-929

Bogner J, Abdelrafie Ahmed M, Diaz C, Faaij A, Gao Q, Hashimoto S, Mareckova K, Pipatti R, Zhang T (2007) Waste management, in climate change 2007: mitigation. Contribution of working group III to the fourth assessment report of the intergovernmental panel on climate change. In: Metz B, Davidson OR, Bosch PR, Dave R, Meyer LA (eds). Cambridge University Press, Cambridge

Boldrin A, Hartling K, Laugen M, Christensen T (2010) Environmental inventory modelling of the use of compost and peat in growth media preparation. Resour Conserv Recycl 54:1250-1260

Calvin K, Clarke L, Edmonds J, Eom J, Hejazi M, Kim S, Kyle P, et al (2011) GCAM Wiki documentation. Pacific Northwest National Laboratory. https://wiki.umd.edu/gcam/index.php/Main_Page

Capellán-Pérez I, González-Eguino M, Arto I, Ansuategi A, Dhavala K, Patel P, Mākandya A (2014) New climate scenario framework implementation in the GCAM integrated assessment model. BC3 Working paper series 2014-04. Basque Centre for Climate Change (BC3), Leioa

Caves DW, Christensen LR (1988) The importance of economies of scale, capacity utilization, and density in explaining interindustry differences in productivity growth. Log Transport Rev 2:3-32

Central Bureau for Statistics (2016) Statistics Netherlands: Personenmobiliteit in Nederland; reiskenmerken en vervoerwijzen, regio's [Data file]. Retrieved from http://statline.cbs.nl/Statweb/publication/?DM= SLNL\&PA $=83498$ NED $\& D 1=3 \& D 2=0 \& D 3=0,6 \& D 4=0-8 \& D 5=0 \& D 6=0-4 \& V W=T$

Chen TD, Kockelman KM (2015) Carsharing's life-cycle impacts on energy use and greenhouse gas emissions. Transport Res Part D Transport and Environ 47:276-284

Corral-Verdugo V, Mireles-Acosta JF, Tapia-Fonllem C, Fraijo-Sing B (2011) Happiness as correlate of sustainable behavior: a study of pro-ecological, frugal, equitable and altruistic actions that promote subjective wellbeing. Human Ecology Rev:95-104

Costanzo M, Archer D, Aronson E, Pettigrew T (1986) Energy conservation behaviour: the difficult path from information to action. Am Psychol 41(5):521

De Hartog JJ, Boogaard H, Nijland H, Hoek G (2010) Do the health benefits of cycling outweigh the risks? Environ Health Perspect:1109-1116

Derraik JG (2002) The pollution of the marine environment by plastic debris: a review. Mar Pollut Bull 44(9): 842-852

Dietz T, Gardner GT, Gilligan J, Stern PC, Vandenbergh MP (2009) Household actions can provide a behavioral wedge to rapidly reduce US carbon emissions. Proc Natl Acad Sci 106(44):18452-18456

Druckman A, Chitnis M, Sorrell S, Jackson T (2011) Missing carbon reductions? Exploring rebound and backfire effects in UK households. Energy Policy 39(6):3572-3581

EIA (2006) Saving energy recycling paper \& glass. Energy Information Administration. September 2006. Retrieved 20 October 2007

EC (2010a) TREMOVE Model V3.3.2, European Commission

EC (2010b) Being wise with waste: the EU's approach to waste management. European Commission. Available at http://ec.europa.eu/environment/waste/pdf/WASTE\%20BROCHURE.pdf

Edmonds J, Reilly J (1985) Global energy: assessing the future. Oxford University Press, New York 
Edmonds J, Wise M, Pitcher H, Richels R, Wigley T, Maccracken C (1997) An integrated assessment of climate change and the accelerated introduction of advanced energy technologies. Mitig Adapt Strateg Glob Chang 1(4):311-339. https://doi.org/10.1007/BF00464886

EPA (2015) Greenhouse gas emissions from management of selected materials in municipal solid waste. Online Waste Reduction Model (Warm) version 12. EPA530-R-98-013. https://www3.epa. gov/climatechange/wycd/waste/downloads/Landfilling.pdf

Zero Waste Europe (2015) The potential contribution of waste management to a low carbon economy. October 2015. https://www.zerowasteeurope.eu/downloads/the-potential-contribution-of-waste-management-to-alow-carbon-economy/

European Declaration on Paper Recycling (EDPR) 2015 Monitoring Report 2014 (2015), 14-10-2015, Available at: http://www.paperrecovery.org/uploads/Modules/Publications/Final_MonitoringReport2014.pdf

Eurostat (2016) Generation of waste by waste category, hazardousness and NACE Rev. 2 activity [Datafile]. Retrieved from http://appsso.eurostat.ec.europa.eu/nui/show.do?dataset=env wasgen\&lang=en

Faber J, Schroten A, Bles M, Sevenster M,Markowska A, Smit M, Rohde C, Dütschke E, Köhler J, Gigli M, Zimmermann K, Soboh R, van't Riet J (2012) Behavioural climate change mitigation options and their appropriate inclusion in quantitative longer term policy scenarios - main report CE Delft. Available at http://www.cedelft.eu/publicatie/behavioural_climate_change_mitigation_options_and_their_appropriate_ inclusion in quantitative longer term policy_scenarios/1290

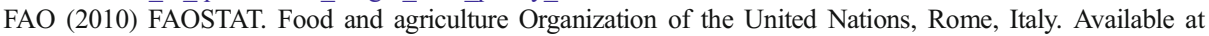
http://faostat.fao.org/

FAO (2011) Global food losses and food waste - extend, causes and prevention. Rome, Italy

Fujii S (2006) Environmental concern, attitude toward frugality, and ease of behavior as determinants of proenvironmental behavior intentions. J Environ Psychol 26(4):262-268

Gadenne D, Sharma B, Kerr D, Smith T (2011) The influence of consumers' environmental beliefs and attitudes on energy saving behaviours. Energy Policy 39(12):7684-7694

GAIA (2012) On the road to zero waste. June, 2012. Available at http://www.no-burn.org/downloads/On\%20 the\%20Road\%20to\%20Zero\%20Waste.pdf

García-Muros X, Markandya A, Romero-Jordán D, González-Eguino M (2017) The distributional effects of carbon-based food taxes. J Clean Prod 140:996-1006

Gifford R (2011) The dragons of inaction: psychological barriers that limit climate change mitigation and adaptation. Am Psychol 66:290-302. https://doi.org/10.1037/a0023566

Gifford R, Kormos C, McIntyre A (2011) Behavioral dimensions of climate change: drivers, responses, barriers, and interventions. WIREs Clim Change. https://doi.org/10.1002/wcc.143

González-Eguino M, Capellán-Pérez I, Arto I, Ansuategi A, Markandya A (2016) Industrial and terrestrial carbon leakage under climate policy fragmentation. Clim Pol. https://doi.org/10.1080/14693062.2016.1227955

Grabs J (2015) The rebound effects of switching to vegetarianism. A microeconomic analysis of Swedish consumption behavior. Ecol Econ 116(2015):270-279

Gustavsen GW, Rickertsen K (2013) Adjusting VAT rates to promote healthier diets in Norway: a censored quantile regression approach. Food Policy 42:88-95

Hallström E, Carlsson-Kanyama A, Börjesson P (2015) Environmental impact of dietary change: a systematic review. J Clean Prod 91:1-11. https://doi.org/10.1016/j.jclepro.2014.12.008

Hards S (2011) Social practice and the evolution of personal environmental values. Environ Values, 23-42

Howell R (2013) It's not (just) "the environment, stupid!" Values, motivations, and routes to engagement of people adopting lower-carbon lifestyles. Glob Environ Chang 23(1):281-290. https://doi.org/10.1016/j. gloenvcha.2012.10.015

Intergovernmental Panel on Climate Change (IPCC) (2006) 2006 IPCC guidelines for national greenhouse gas inventories. Prepared by the National Greenhouse Gas Inventories Programme. Eggleston HS, Buendia L, Miwa K, Ngara T and Tanabe K (eds). IGES, Japan

Intergovernmental Panel on Climate Change (IPCC) (2014) Climate change 2014-impacts, adaptation and vulnerability: regional aspects. Cambridge University Press, Cambridge

IPCC (2007) Summary for Policymakers, in Climate Change 2007: mitigation. Contribution of working group III to the fourth assessment report of the intergovernmental panel on climate change. In: Metz B, Davidson OR, Bosch PR, Dave R, Meyer LA (eds) Cambridge University Press, Cambridge, United Kingdom and New York, NY, USA

Jacob J, Jovic E, Brinkerhoff MB (2009) Personal and planetary well-being: mindfulness meditation, proenvironmental behavior and personal quality of life in a survey from the social justice and ecological sustainability movement. Soc Indic Res 93(2):275-294

Kaida N, Kaida K (2016) Pro-environmental behavior correlates with present and future subjective well-being. Environ Dev Sustain 18(1):111-127 
Kummu M, De Moel H, Porkka M, Siebert S, Varis O, Ward PJ (2012) Lost food, wasted resources: global food supply chain losses and their impacts on freshwater, cropland, and fertiliser use. Sci Total Environ 438:477-489

Kyle GP, Luckow P, Calvin KV, Emanuel B, Nathan M, Zhou Y (2011) GCAM 3.0 Agriculture and land use: data sources and methods. PNNL-21025. Pacific Northwest National Laboratory, Richland

Kyle P, Clarke L, Rong F, Smith S (2010) Climate policy and the long-term evolution of the U.S. building sector. Energy J 31(3):131-158

Laestadius LI, Neff RA, Barry CL, Frattaroli S (2014) "We don't tell people what to do": an examination of the factors influencing NGO decisions to campaign for reduced meat consumption in light of climate change. Glob Environ Chang 29:32-40

Lange H, Meier L (2009) The new middle classes. Globalizing lifestyles, consumerism and environmental concern. Springer, Dordrecht

Lin SP (2013) The gap between global issues and personal behaviors: pro-environmental behaviors of citizens toward climate change in Kaohsiung, Taiwan. Mitig Adapt Strateg Glob Chang 18(6):773-783

Lorenzoni I, Nicholson-Cole S, Whitmarsh L (2007) Barriers perceived to engaging with climate change among the UK public and their policy implications. Glob Environ Chang 17(3):445-459

Lusk JL, Schroeter C (2012) When do fat taxes increase consumer welfare? Health Econ 21(11):1367-1374

Masud MM, Akhtar R, Afroz R, Al-Amin AQ, Kari FB (2015) Pro-environmental behavior and public understanding of climate change. Mitig Adapt Strateg Glob Chang 20(4):591-600

Mishra GS, Kyle P, Teter J, Morrison G, Yeh S, and Kim S (2013) Transportation module of global change assessment module (GCAM): model documentation version 1.0. Institute of Transportation Studies, University of California at Davis; and Pacific Northwest National Laboratory. Report UCD-ITS-RR-1305. June 2013.

Mont O (2004) Institutionalisation of sustainable consumption patterns based on shared use. Ecol Econ 50(1-2): 135-153

Moser SC (2010) Communicating climate change: history, challenges, process and future directions. Wiley Interdiscip Rev Clim Chang 1(1):31-53

O’Neill BC, Kriegler E, Ebi KL, Kemp-Benedict E, Riahi K, Rothman DS, van Ruijven BJ, van Vuuren DP, Birkmann J, Kok K, Levy M, Solecki W (2017) The roads ahead: narratives for shared socioeconomic pathways describing world futures in the 21st century. Glob Environ Chang 42:169-180

O’Neill BC, Kriegler E, Riahi K, Ebi KL, Hallegatte S, Carter TR, Mathur R, van Vuuren DP (2014) A new scenario framework for climate change research: the concept of shared socioeconomic pathways. Clim Chang 122(3):387-400

O'Neill S, Nicholson-Cole S (2009) "Fear won't do it" promoting positive engagement with climate change through visual and iconic representations. Sci Commun 30(3):355-379

Ohe M, Ikeda S (2005) Global warming: risk perception and risk-mitigating behavior in Japan. Mitig Adapt Strateg Glob Chang 10(2):221-236

Ohtomo S, Hirose Y (2007) The dual-process of reactive and intentional decision-making involved in ecofriendly behavior. J Environ Psychol 27(2):117-125

Ozaki R (2011) Adopting sustainable innovation: what makes consumers sign up to green electricity? Bus Strateg Environ 20(1):1-17

Pacala S, Socolow R (2004) Stabilization wedges: solving the climate problem for the next 50 years with current technologies. Science 305(5686):968-972

Poortinga W, Steg L, Vlek C (2004) Values, environmental concern, and environmental behavior a study into household energy use. Environ Behav 36(1):70-93

Quimby CC, Angelique H (2011) Identifying barriers and catalysts to fostering pro-environmental behavior: opportunities and challenges for community psychology. Am J Community Psychol 47(3-4):388-396

Roy J (2012) Lifestyles, well-being and energy. Glob Energy Assess 1527-1548

Samadi S, Gröne MC, Schneidewind U, Luhmann HJ, Venjakob J, Best B (2017) Sufficiency in energy scenario studies: taking the potential benefits of lifestyle changes into account. Technol Forecast Soc Chang (in press)

Schäfer M, Jaeger-Erben M, dos Santos A (2011) Leapfrogging to sustainable consumption? An explorative survey of consumption habits and orientation in Southern Brazil. J Consumer Policy. https://doi.org/10.1007 /s10603-010-9150-5

Schmitt MT, Aknin LB, Axsen J, Shwom RL (2018) Unpacking the relationships between pro-environmental behavior, life satisfaction, and perceived ecological threat. Ecol Econ 143:130-140

Semenza JC, Hall DE, Wilson DJ, Bontempo BD, Sailor DJ, George LA (2008) Public perception of climate change: voluntary mitigation and barriers to behavior change. Am J Prev Med 35(5):479-487

Sheppard SR (2005) Landscape visualisation and climate change: the potential for influencing perceptions and behaviour. Environ Sci Pol 8(6):637-654

Shwom R, Lorenzen JA (2012) Changing household consumption to address climate change: social scientific insights and challenges. Wiley Interdiscip Rev Clim Chang 3(5):379-395 
Staats H, Harland P, Wilke HA (2004) Effecting durable change a team approach to improve environmental behavior in the household. Environ Behav 36(3):341-367

Stehfest E, Bouwman L, van Vuuren DP, Den Elzen MG, Eickhout B, Kabat P (2009) Climate benefits of changing diet. Clim Chang 95(1-2):83-102

Suárez-Varela M, Guardiola J, González-Gómez F (2016) Do pro-environmental behaviors and awareness contribute to improve subjective well-being? Appl Res Quality Life 11(2):429-444

Sullivan AB, Wang M (2010) Energy-consumption and carbon-emission analysis of vehicle and component manufacturing. Argonne National Laboratory, Lemont

The Economist (2007) The price of virtue. June 7, 2007. Available at http://www.economist.com/node/9302727

Thomson AM, Calvin KV, Smith SJ, Kyle GP, Volke A, Patel P, Edmonds JA (2011) RCP4. 5: a pathway for stabilization of radiative forcing by 2100. Climatic Change 109(1-2):77

Thow AM, Downs S, Jan S (2014) A systematic review of the effectiveness of food taxes and subsidies to improve diets: understanding the recent evidence. Nutr Rev 72(9):551-565

Transportation Research Board (2005) Transit Cooperative Research Program (TCRP). Report 108. Adam Millard-Ball, Gail Murray, Jessica ter Schure, Christine Fox, Nelson Nygaard Consulting Assoc., and Jon Burkhardt, Westat

van Sluisveld MA, Martinez SH, Daioglou V, van Vuuren DP (2016) Exploring the implications of lifestyle change in $2 \mathrm{C}$ mitigation scenarios using the IMAGE integrated assessment model. Technol Forecast Soc Chang 102:309-319

van Westerhoven M (2013) Bepaling voedselverliezen in huishoudelijk afval in Nederland, Vervolgmeting 2013, CREM Amsterdam in opdracht van het ministerie van Infrastructuur en Milieu

Ventour L (2008) The food we waste. WRAP food waste report v2. Available at http://wrap.s3.amazonaws. com/the-food-we-waste.pdf. Accessed 31 May 2016

Welsch H, Kühling J (2011) Are pro-environmental consumption choices utility-maximizing? Evidence from subjective well-being data. Ecol Econ 72:75-87

Whitmarsh L (2009) Behavioural responses to climate change: Asymmetry of intentions and impacts. J Environ Psychol 29(1):13-23

WHO (2003) WHO \& FAO joint WHO/FAO expert consultation on diet. Nutrition and the prevention of chronic diseases

Willett W (2011) Eat, drink, and be healthy: the Harvard Medical School guide to healthy eating. Simon and Schuster, New York

Wynes S, Nicholas KA (2017) The climate mitigation gap: education and government recommendations miss the most effective individual actions. Environ Res Lett, 12(7)

Xiao JJ, Li H (2011) Sustainable consumption and life satisfaction. Soc Indic Res 104(2):323-329 